Supporting Information

\title{
Electrochemical Synthesis, Deposition, and Doping of Polycyclic Aromatic
}

\section{Hydrocarbon Films}

Cheng Zeng, ${ }^{\dagger, \#}$ Bohan Wang, ${ }^{\dagger, \#}$ Huanhuan Zhang, ${ }^{\dagger, \#}$ Mingxiao Sun, ${ }^{\dagger}$ Liangbin Huang,,

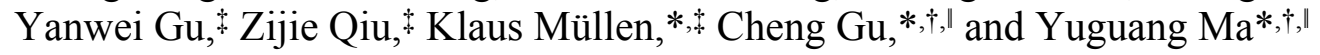

†State Key Laboratory of Luminescent Materials and Devices, Institute of Polymer Optoelectronic Materials and Devices, South China University of Technology, Guangzhou 510640, P. R. China

*Max Planck Institute for Polymer Research, Ackermannweg 10, 55128 Mainz, Germany

§School of Chemistry and Chemical Engineering, South China University of Technology. Guangzhou 510641, P. R. China

'Guangdong Provincial Key Laboratory of Luminescence from Molecular Aggregates, South China University of Technology, Guangzhou 510640, P. R. China

\section{Table of Contents}

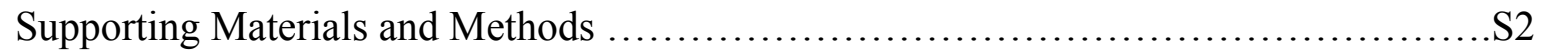

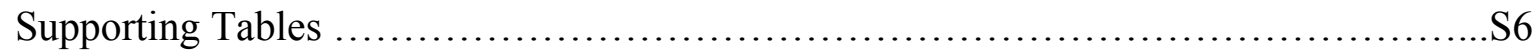

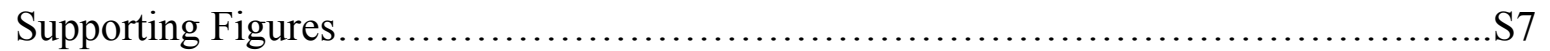

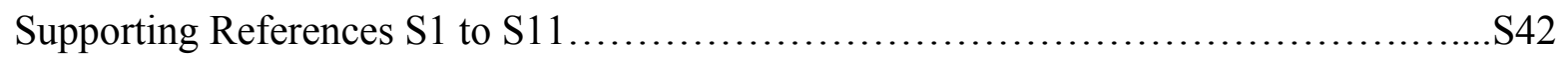




\section{Supplementary Materials and Methods}

\section{Materials and synthetic procedures.}

Dichloromethane $(\mathrm{DCM})$, tetrabutylammonium hexafluorophosphate $\left(\mathrm{Bu}_{4} \mathrm{NPF}_{6}\right)$, potassium ferricyanide $\left(\mathrm{K}_{3} \mathrm{Fe}(\mathrm{CN})_{6}\right)$, potassium chloride $(\mathrm{KCl})$, and 2,3-dichloro-4,5-dicyanopara-benzoquinone (DDQ) were purchased from $\mathrm{J} \& \mathrm{~K}$ chemical. Acetonitrile (ACN) was purchased from Sigma Aldrich. Precursor 1 (1,3,5-tris(2'-(4"-phenyl)biphenyl)benzene), 2 (3',3"',4',4"',5',5'",6',6"'-octaphenyl-1,1':2',1":4",1'":2'",1"'--quinquephenyl), and 3 (5"-(3',6'diphenyl-[1,1':2',1"-terphenyl]-4'-yl)-3"',4',4"',5',5"',6'-hexaphenyl-1,1':2',1":3",1"':2"',1'"'quinquephenyl) and their chemically synthesized products were synthesized according to literature procedures. ${ }^{\mathrm{S} 1-\mathrm{S} 3}$

Electrochemical synthesis of PAH C60 films. The PAH C60 films were electrochemically synthesized from precursor $1\left(7.87 \times 10^{-4} \mathrm{~mol} \mathrm{~L}^{-1}\right.$ in electrolyte solution) in a three-electrode system using glassy carbon or ITO as the working electrode, a Pt wire or titanium plate as the counter electrode, and an $\mathrm{Ag} / \mathrm{Ag}^{+}$(ACN containing $0.01 \mathrm{M} \mathrm{AgNO}_{3}$ and $0.1 \mathrm{M} \mathrm{Bu}_{4} \mathrm{NPF}_{6}$ was used as internal reference solution) as the reference electrode. DCM with supporting electrolyte $\left(0.1 \mathrm{M} \mathrm{Bu}_{4} \mathrm{NPF}_{6}\right)$ was used as electrolyte solution. Electrochemical oxidation was conducted by using multicycle $\mathrm{CV}$ in the potential range from -0.5 to $1.65 \mathrm{~V}$. In addition to applying the $\mathrm{CV}$ method, the PAHs were also prepared on ITO by potentiostatic method of precursors at $1.65 \mathrm{~V}$, followed by applying a potential at $-1 \mathrm{~V}$ for $200 \mathrm{~s}$ to neutralize the cationic species. This method yields micrometer-thick films that can be easily scraped off the electrodes to form powders with a sufficient mass for analysis. After the deposition was completed, the films were washed with DCM to remove doped counterions. All electrochemical experiments were carried out in a glove box (nitrogen atmosphere). The product structures were characterized by matrix-assisted laser-desorption time-of-flight mass spectrometry (MALDI-TOF MS), Fourier transform infrared (FT-IR), and Raman spectroscopy.

Electrochemical synthesis of PAH C78 films. The PAH C78 films were electrochemically synthesized from precursor $2\left(1.01 \times 10^{-4} \mathrm{~mol} \mathrm{~L}^{-1}\right.$ in electrolyte solution) in a three-electrode system using glassy carbon or ITO as the working electrode, a Pt wire or titanium plate as the counter electrode, and an $\mathrm{Ag} / \mathrm{Ag}^{+}$as the reference electrode. A mixture 
of DCM/ACN (4:1 v/v) with supporting electrolyte $\left(0.1 \mathrm{M} \mathrm{Bu}_{4} \mathrm{NPF}_{6}\right)$ was used as electrolyte solution. Electrochemical oxidation was conducted by using multicycle $\mathrm{CV}$ in the potential range from -0.5 to $1.65 \mathrm{~V}$. In addition to applying the $\mathrm{CV}$ method, the PAHs were also prepared on ITO by potentiostatic method of precursors at $1.65 \mathrm{~V}$, followed by applying a potential at $-1 \mathrm{~V}$ for $200 \mathrm{~s}$ to neutralize the cationic species. This method yields micrometerthick films that can be easily scraped off the electrodes to form powders with a sufficient mass for analysis. After the deposition was completed, the films were washed with DCM to remove doped counterions. All electrochemical experiments were carried out in a glove box (nitrogen atmosphere). The product structures were characterized by MALDI-TOF MS, FTIR, and Raman spectroscopy.

Electrochemical synthesis of PAH C96 films. The PAH C96 films were electrochemically synthesized from precursor $3\left(8.21 \times 10^{-4} \mathrm{~mol} \mathrm{~L}^{-1}\right.$ in electrolyte solution) in a three-electrode system using glassy carbon or ITO as the working electrode, a Pt wire or titanium plate as the counter electrode, and an $\mathrm{Ag} / \mathrm{Ag}^{+}$as the reference electrode. DCM with supporting electrolyte $\left(0.1 \mathrm{M} \mathrm{Bu}_{4} \mathrm{NPF}_{6}\right)$ was used as electrolyte solution. Electrochemical oxidation was conducted using potentiostatic method at $2.35 \mathrm{~V}$, followed by applying a potential at $-1 \mathrm{~V}$ for $200 \mathrm{~s}$ to neutralize the cationic species. This method yields micrometerthick films that can be easily scraped off the electrodes to form powders with a sufficient mass for analysis. After the deposition was completed, the films were washed with DCM to remove doped counterions. All electrochemical experiments were carried out in a glove box (nitrogen atmosphere). The product structures were characterized by MALDI-TOF MS, FTIR, and Raman spectroscopy.

\section{Electrochemical synthesis of PAH C96 films with 2,3-dichloro-4,5-dicyano-para-} benzoquinone (DDQ) as mediator. The PAH C96 films were electrochemically synthesized from precursor $3\left(8.21 \times 10^{-4} \mathrm{~mol} \mathrm{~L}^{-1}\right.$ in electrolyte solution) in a three-electrode divided $\mathrm{H}$ type cell system using glassy carbon or ITO as the working electrode, a Pt wire or titanium plate as the counter electrode, and an $\mathrm{Ag} / \mathrm{Ag}^{+}$as the reference electrode. A mixture of TFA/ $\operatorname{DCM}(1: 9 \mathrm{v} / \mathrm{v})$ with supporting electrolyte $\left(0.1 \mathrm{M} \mathrm{Bu}_{4} \mathrm{NPF}_{6}\right)$ was used as electrolyte solution. Precursors and DDQ $(5 \mathrm{~mol} \%)$ as mediator were added only in the cambers of anode. Electrochemical oxidation was conducted using potentiostatic method at $1.50 \mathrm{~V}$, followed by applying a potential at $-1 \mathrm{~V}$ for $200 \mathrm{~s}$ to neutralize the cationic species. This method yields 
micrometer-thick films that can be easily scraped off the electrodes to form powders with a sufficient mass for analysis. After the deposition was completed, the films were washed with DCM to remove doped counterions. All electrochemical experiments were carried out in a glove box (nitrogen atmosphere). The product structures were characterized by MALDI-TOF MS, FT-IR, and Raman spectroscopy.

\section{Methods and instruments.}

Electrochemical experiments were performed on a CHI 760D electrochemical workstation. The film thickness was measured on a Veeco dektal 150 profilometer. The MALDI measurements for solid-state samples were carried out on a rapifleXTM MALDITOF/TOF mass spectrometer from Bruker Daltonik GmbH using 7,7,8,8tetracyanoquinodimethane (TCNQ) as the matrix. The instrument is equipped with a $10 \mathrm{kHz}$ scanning smartbeam Nd:YAG laser at a wavelength of $355 \mathrm{~nm}$ and a 10 bit $5 \mathrm{GHz}$ digitizer. FT-IR spectra were measured using an IFS 66V/S Fourier transform infrared spectrophotometer. A micro-Raman spectrometer (Renishaw, InVia Microscope) with a 532 $\mathrm{nm}$ laser was used in the Raman study. UV-vis spectra were recorded on a Shimadzu UV3600 spectrophotometer. Field-emission scanning electron microscopy (FE-SEM) was performed on a Zeiss Merlin operating at an accelerating voltage of $5.0 \mathrm{kV}$. The powder Xray diffraction study was performed on a Bruker D8 ADVANCE diffractometer using Cu K- $\alpha$ X-ray, at $40 \mathrm{kV}, 40 \mathrm{~mA}$. XPS was performed on ThermoFisher ESCALAB XI+.

The structure of partially cyclodehydrogenated PAH C96 were calculated using densityfunctional theory ${ }^{\mathrm{S}, \mathrm{S} 5}$ (DFT) implemented in the CASTEP $\mathrm{C}^{\mathrm{S} 6}$ module of Materials Studio 7.0. The generalized gradient approximation (GGA) in the form of Perdew-Burke-Ernzerhof $(\mathrm{PBE})^{\mathrm{S} 7}$ was selected as the exchange-correlation functional. Grimme dispersion correction $^{\mathrm{S} 8 \mathrm{~S} 9}$ was employed in all calculations to describe van der Waals (vdW) and $\pi$ stacking interactions. All simulation works were performed using the computing resources at National Supercomputing Center in Shenzhen.

\section{Calibrating active surface areas of electrodes.}

The active surface areas (non-apparent area) of glassy carbons were calibrated as follows: the electrodes to be tested was placed in an aqueous solution contained $\mathrm{K}_{3} \mathrm{Fe}(\mathrm{CN})_{6}\left(5.0 \times 10^{-3}\right.$ mol L-1) and $\mathrm{KCl}\left(1 \mathrm{~mol} \mathrm{~L}^{-1}\right)$, and the $\mathrm{CV}$ curves was recorded in the range of -0.25 to $0.75 \mathrm{~V}$ (vs. $\mathrm{Ag} / \mathrm{AgCl}$ ). Based on Randles-Sevcik equation ${ }^{\mathrm{S} 10}$ : 


$$
i_{p}=2.69 \times 10^{5} \mathrm{An}^{3 / 2} D_{0}^{1 / 2} C_{0} v^{1 / 2}
$$

where $i_{p}$ is reduction peak current, $A$ is active surface area of electrode, $n$ is electron-transfer number, $C_{0}$ is bulk concentration of $\mathrm{K}_{3} \mathrm{Fe}(\mathrm{CN})_{6}, D_{0}$ is diffusion coefficient and $v$ is scan rate. In this case, $D_{0}=7.6 \times 10^{-6} \mathrm{~cm}^{2} \mathrm{~s}^{-1}(298 \mathrm{~K}) ; n=1 ; C_{0}=5.0 \times 10^{-3} \mathrm{~mol} \mathrm{~L}^{-1} ; v=0.05 \mathrm{~V} \mathrm{~s}^{-1}$. ${ }^{1} 11$

\section{Doping content.}

The doping content of PAH films were represented by the weight fraction of counter ions (doping electrolyte solution: $0.1 \mathrm{M} \mathrm{Bu}_{4} \mathrm{NPF}_{6}$ in $\mathrm{ACN}$ ), for positive doping, which can be obtained as follows:

$$
w t \%=\frac{n_{P A H} \times a t_{P} \% \times M_{i o n}}{a t_{C} \% \times M_{P A H}+n_{P A H} \times a t_{P} \% \times M_{i o n}}
$$

for negative doping, which can be obtained as follows:

$$
w t \%=\frac{\left(n_{P A H}+n_{i o n}\right) \times a t_{\mathrm{N}} \% \times M_{i o n}}{a t_{C} \% \times M_{P A H}+\left(n_{P A H}+n_{i o n}\right) \times a t_{\mathrm{N}} \% \times M_{i o n}}
$$

where $n_{\mathrm{PAH}}$ is the number of carbons in a PAH molecule, $n_{\text {ion }}$ is the number of carbons in a counter ion, $a t_{\mathrm{C}} \%, a t_{\mathrm{P}} \%$, and $a t_{\mathrm{N}} \%$ are the atomic fraction of $\mathrm{C}, \mathrm{P}$ and $\mathrm{N}$ elements (obtained from XPS), respectively, $M_{\mathrm{PAH}}$ and $M_{\text {ion }}$ are the molecular weights of PAHs and counter ions, $\mathrm{wt} \%$ is the weight fraction of counter ions. 


\section{Supporting Tables}

Table S1. The doping content of PAH C60, PAH C78 and PAH C96 films.

\begin{tabular}{|c|c|}
\hline Sample & Doping content (wt\%) \\
\hline pristine PAH C60 films & $/$ \\
\hline 1.30 V doped PAH C60 films & 6.68 \\
\hline-1.90 V doped PAH C60 films & 19.3 \\
\hline pristine PAH C78 films & $/$ \\
\hline 0.57 V doped PAH C78 films & 10.7 \\
\hline-1.60 V doped PAH C78 films & 20.9 \\
\hline pristine PAH C96 films & $/$ \\
\hline 0.95 V doped PAH C96 films & 8.9 \\
\hline-1.77 V doped PAH C96 films & 23.9 \\
\hline
\end{tabular}




\section{Supporting Figures}

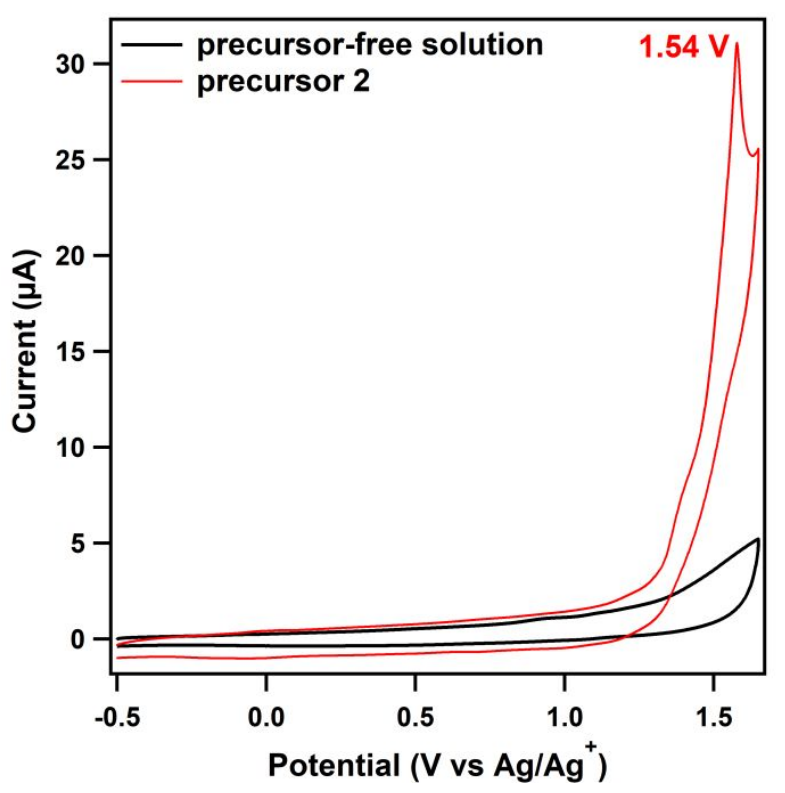

Figure S1. CV profile ( $1^{\text {st }}$ cycle) of a precursor-free solution and solution of precursor 2 with a scan rate of $0.05 \mathrm{~V} \mathrm{~s}^{-1}$ on glassy carbon. The electric current density of precursor 2 at 1.54 $\mathrm{V}$ (oxidation peak) is $582.66 \mu \mathrm{A} \mathrm{cm}^{-1}$, which was more than 8-times higher than precursorfree solution $\left(66.61 \mu \mathrm{A} \mathrm{cm}^{-1}\right)$. 


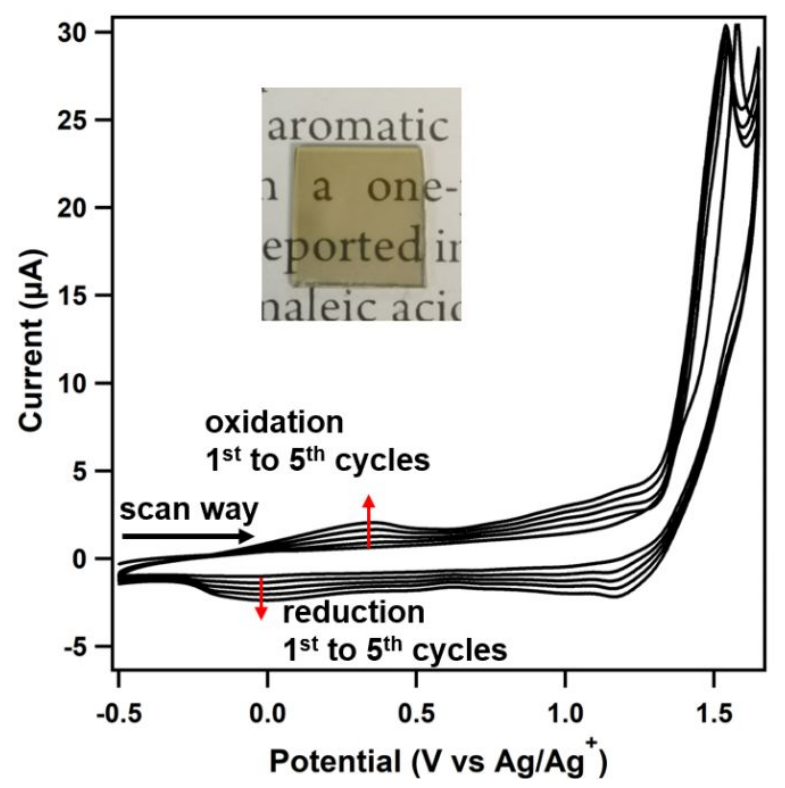

Figure S2. CV profiles ( $1^{\text {st }}$ to $5^{\text {th }}$ cycles) of a solution of precursor 2 to afford PAH C78 with a scan rate of $0.05 \mathrm{~V} \mathrm{~s}^{-1}$ on glassy carbon, including a photo of the transparent PAH C78 film on ITO $\left(1.0 \times 1.0 \mathrm{~cm}^{2}\right.$ in area). 


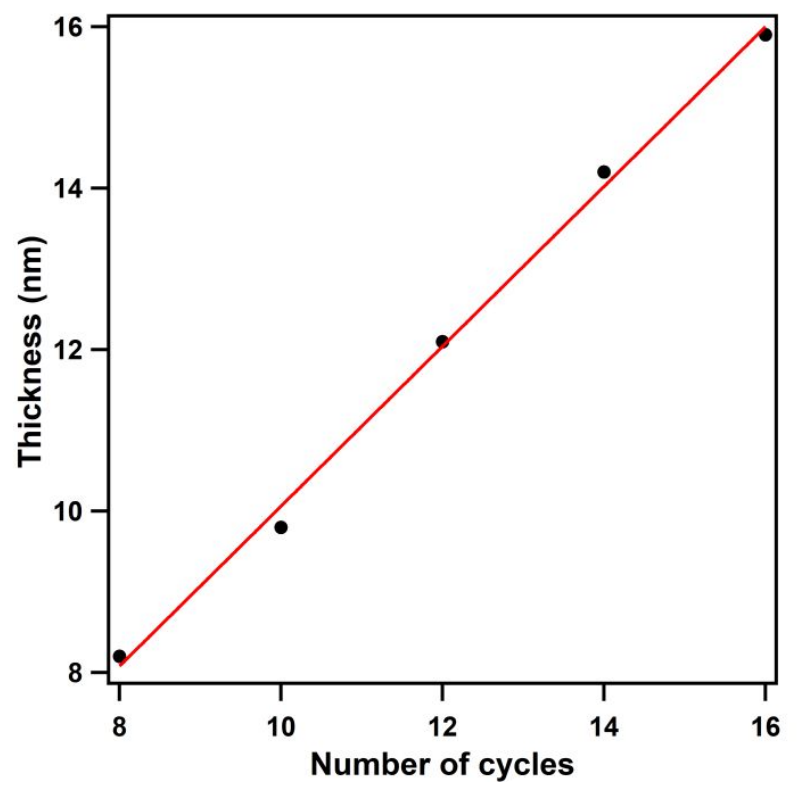

Figure S3. Film thickness versus the CV cycle numbers for PAH C78 films. 


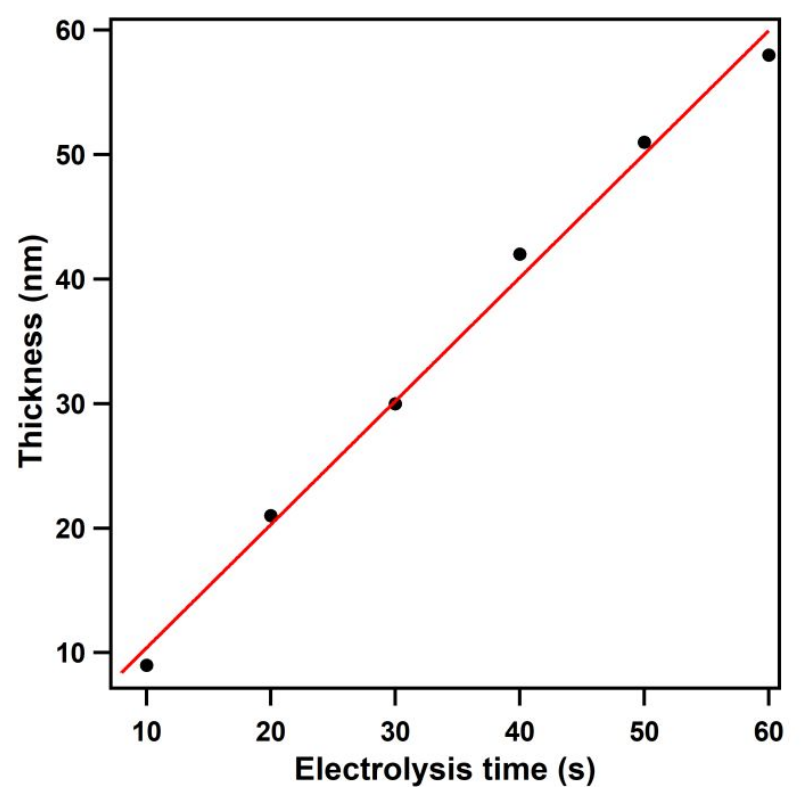

Figure S4. Film thickness versus the electrolysis time for PAH C60 films. 


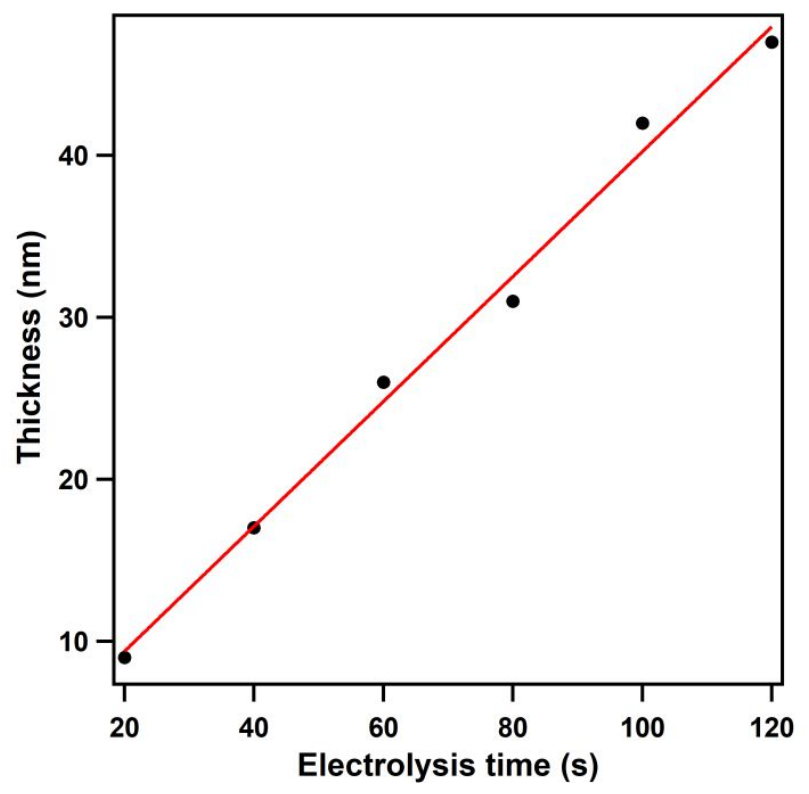

Figure S5. Film thickness versus the electrolysis time for PAH C78 films. 


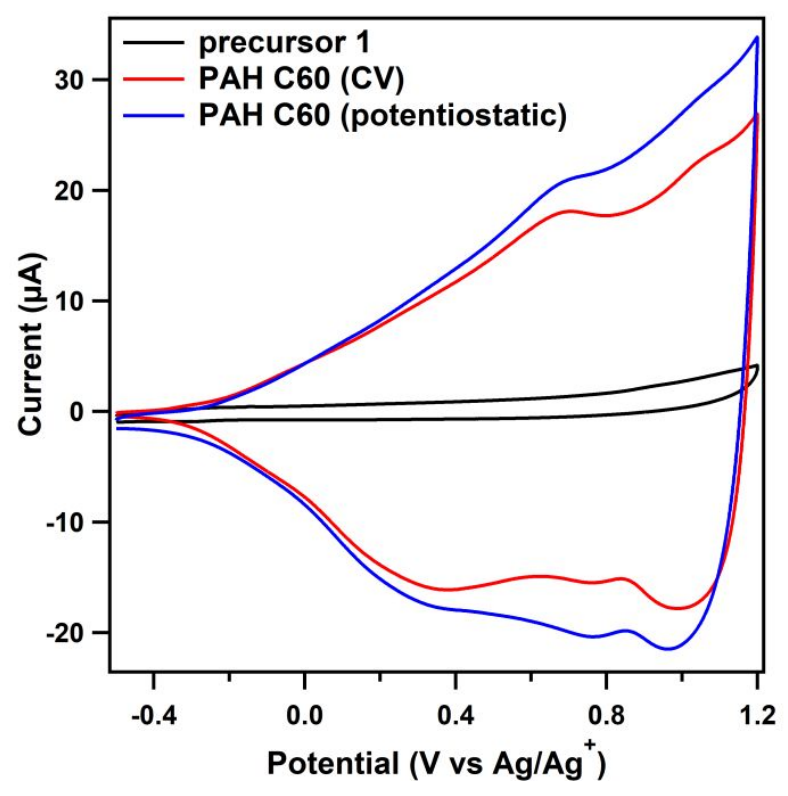

Figure S6. CV profiles ( $1^{\text {st }}$ cycle) of precursor 1 and PAH C60 films (afforded by CV and potentiostatic method, in a precursor-free $\mathrm{DCM}$ solution with $0.1 \mathrm{M} \mathrm{Bu}_{4} \mathrm{NPF}_{6}$ ) with a scan rate of $0.05 \mathrm{~V} \mathrm{~s}^{-1}$ on glassy carbon. 


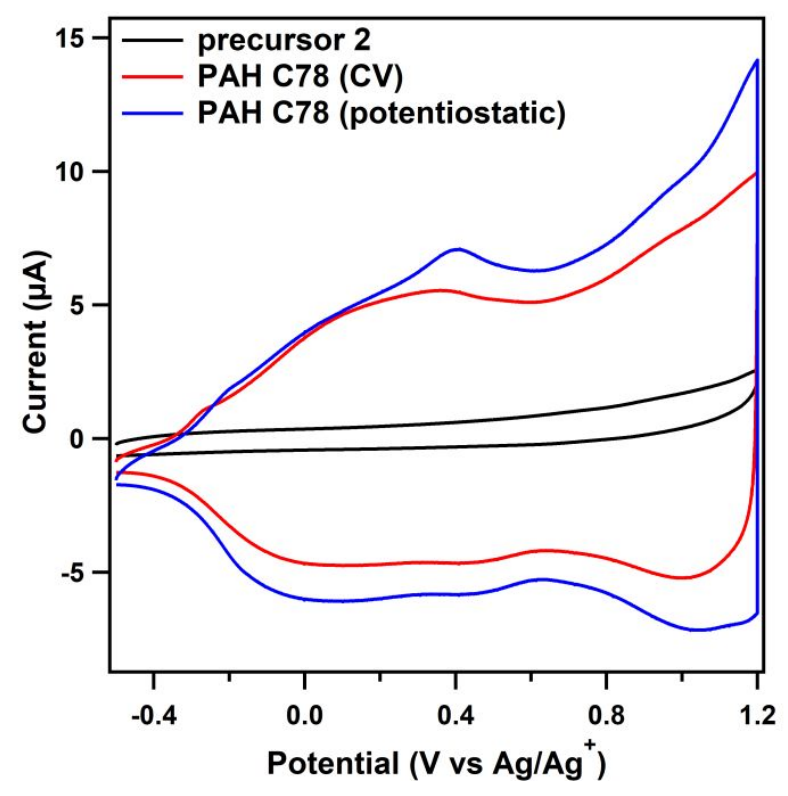

Figure S7. CV profiles ( $1^{\text {st }}$ cycle) of precursor 2 and PAH C78 films (afforded by CV and potentiostatic method, in a precursor-free $\mathrm{DCM}$ solution with $0.1 \mathrm{M} \mathrm{Bu}_{4} \mathrm{NPF}_{6}$ ) with a scan rate of $0.05 \mathrm{~V} \mathrm{~s}^{-1}$ on glassy carbon. 

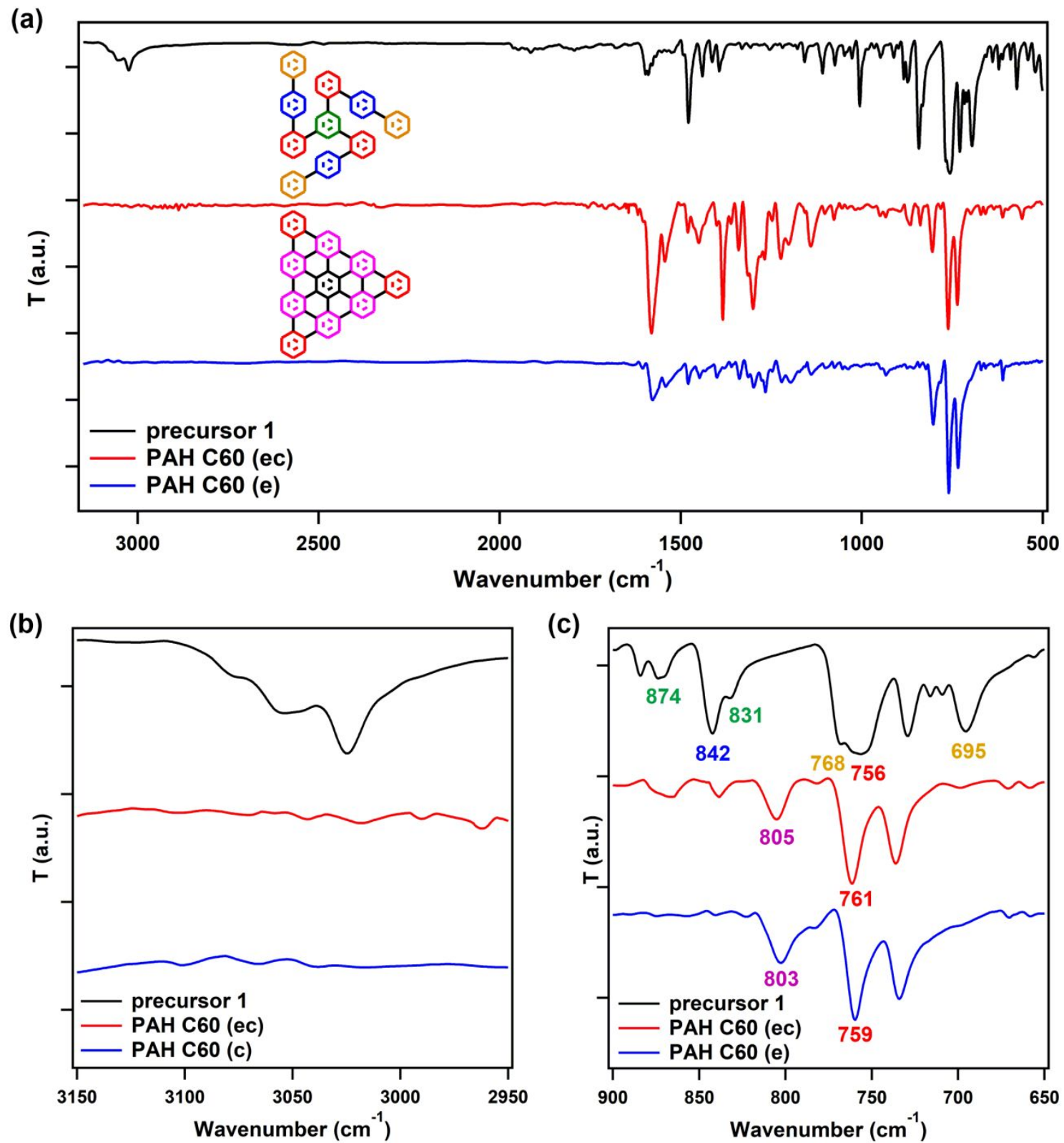

Figure S8. FT-IR of precursor 1 and electrochemically (ec) and chemically (c) synthesized PAH C60 powder. (a) $3200-500 \mathrm{~cm}^{-1}$. (b) $3150-2950 \mathrm{~cm}^{-1}$. (c) $900-650 \mathrm{~cm}^{-1}$

For precursor 1, the medium strong bands at $\sim 3050 \mathrm{~cm}^{-1}$ were related to the $\mathrm{C}-\mathrm{H}$ stretching vibration of the monosubstituted phenyl rings. 


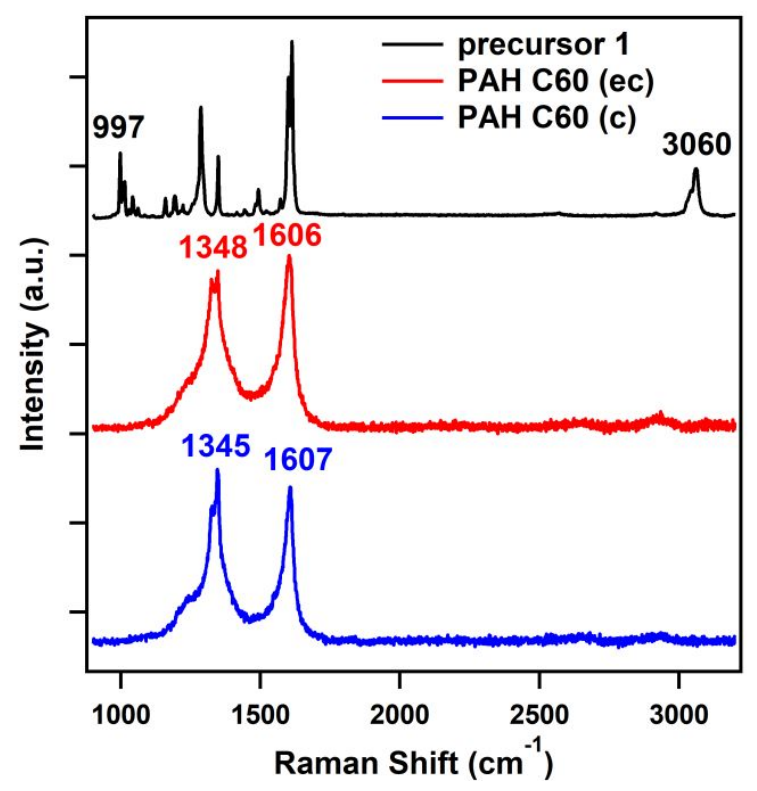

Figure S9. Raman spectra of precursor 1 and electrochemically (ec) and chemically (c) synthesized PAH C60. The peaks at $3060 \mathrm{~cm}^{-1}$ were related to the stretching vibrational bands of $\mathrm{C}-\mathrm{H}$ bonds of phenyl rings. The peaks at $997 \mathrm{~cm}^{-1}$ were related to the in-plane flexural vibration of the benzene ring. For PAH C60, the peaks at 1348 (1345) and 1606 (1607) $\mathrm{cm}^{-1}$ were $\mathrm{D}$ band and $\mathrm{G}$ band, respectively. 


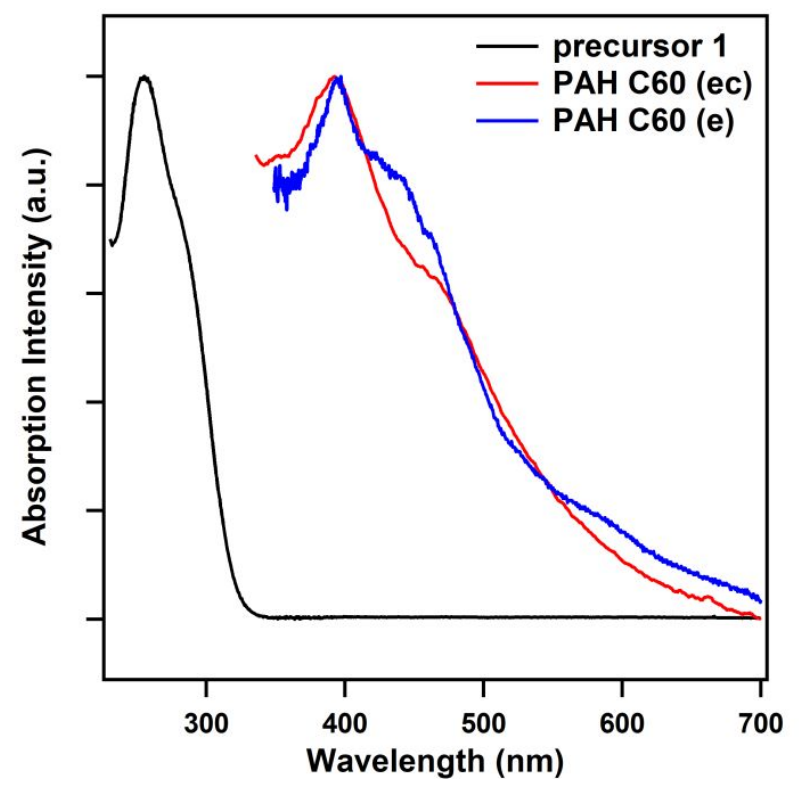

Figure S10. Absorption spectra of precursor 1 and electrochemically (ec) and chemically (c) synthesized PAH C60. The absorption peaks of PAH C60 films show an apparent red shift compared to their precursors, which clearly testifies the formation of an extended conjugation. 


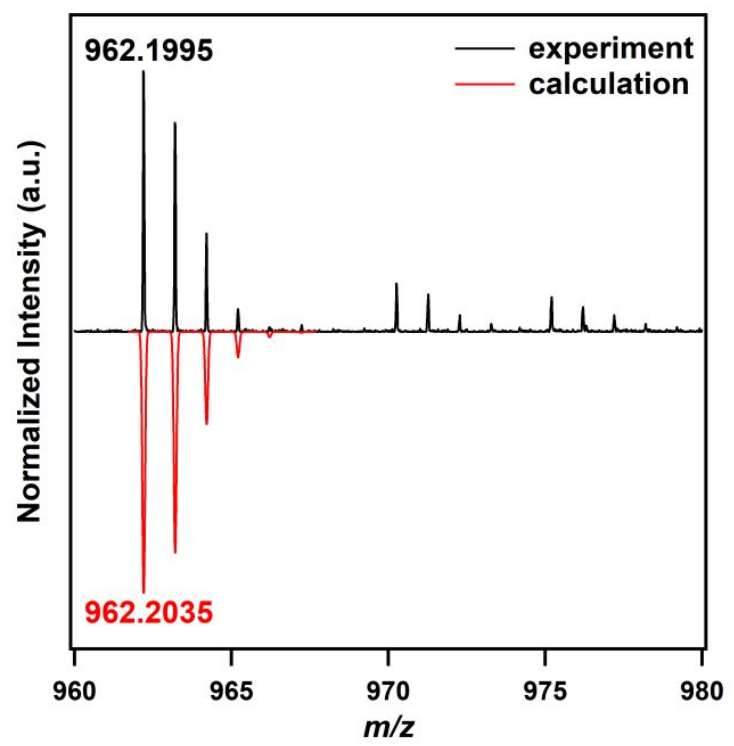

Figure S11. Experimental and calculated MALDI-TOF MS of PAH C78. 

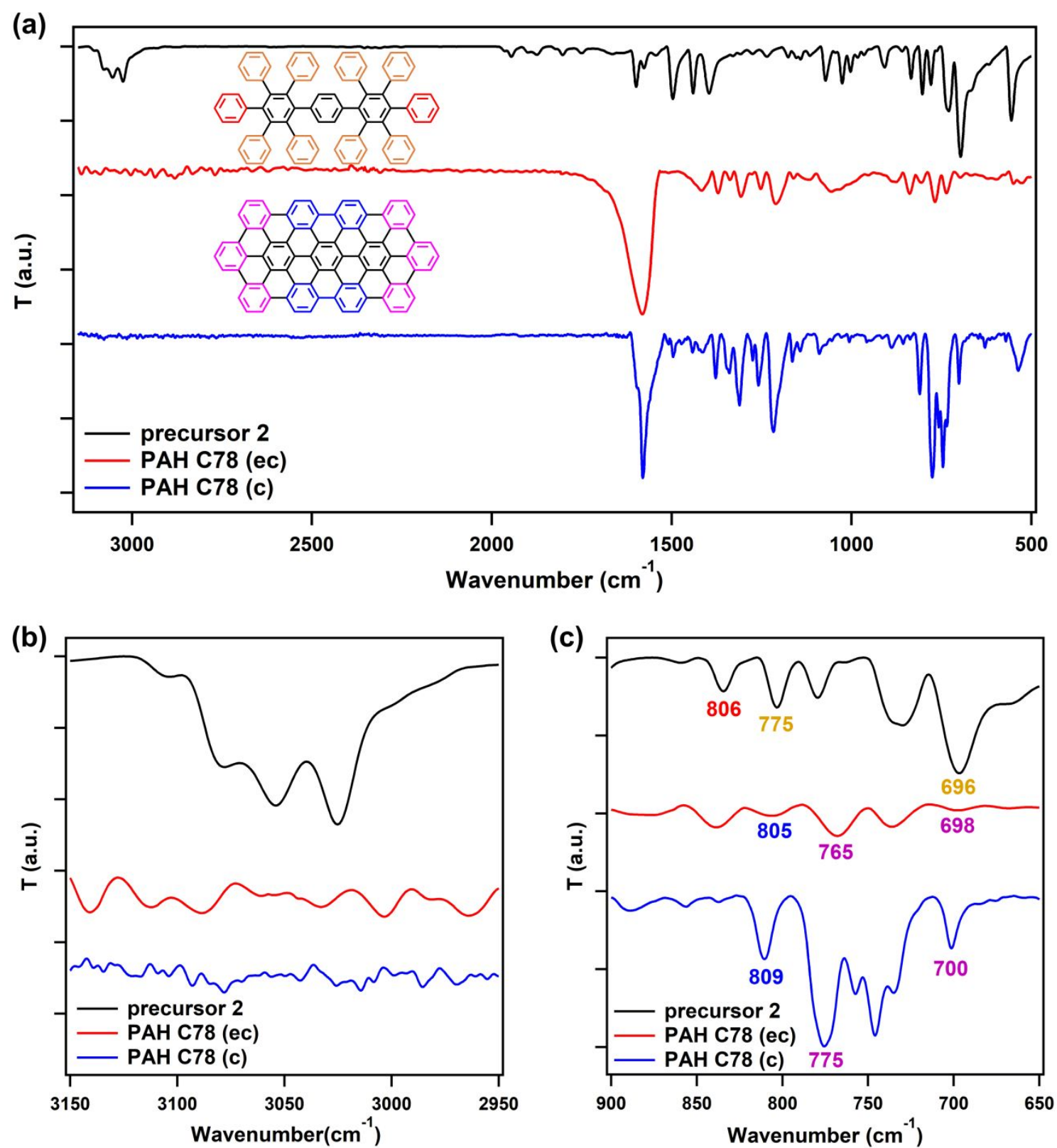

Figure S12. FT-IR of precursor 2 and electrochemically (ec) and chemically (c) synthesized PAH C78 powder. (a) $3200-500 \mathrm{~cm}^{-1}$. (b) $3150-2950 \mathrm{~cm}^{-1}$. (c) $900-650 \mathrm{~cm}^{-1}$.

For precursor 2, the medium strong bands at $\sim 3050 \mathrm{~cm}^{-1}$ were related to the $\mathrm{C}-\mathrm{H}$ stretching vibration of the monosubstituted phenyl rings. The medium strong bands appeared at 775 and $696 \mathrm{~cm}^{-1}$ were contributed to $\mathrm{C}-\mathrm{H}$ twisting vibrations of the monosubstituted phenyl rings (phenyl units in orange). The peaks located at $806 \mathrm{~cm}^{-1}$ were produced by the $\mathrm{C}-$ $\mathrm{H}$ twisting vibrations of the 1,4-disubstituted benzenes (phenyl units in red). For PAH C78, the peaks located at $765(775)$ and $698(700) \mathrm{cm}^{-1}$ were produced by the $\mathrm{C}-\mathrm{H}$ twisting vibrations of the 1,2,3-trisubstituted benzenes (phenyl units in purple). The peaks located at $805(809) \mathrm{cm}^{-1}$ was produced by the $\mathrm{C}-\mathrm{H}$ twisting vibrations of the 1,2,3,4-tetrasubstituted benzenes (phenyl units in blue). 


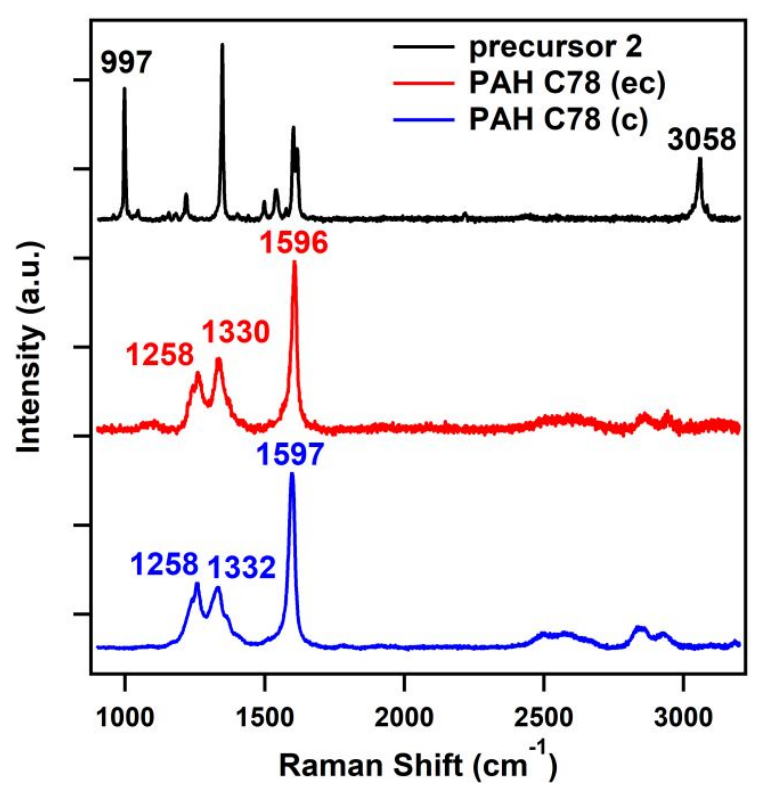

Figure S13. Raman spectra of precursor 2 and electrochemically (ec) and chemically (c) synthesized PAH C78. For precursor 2, the peaks at $3058 \mathrm{~cm}^{-1}$ were related to the stretching vibrational bands of $\mathrm{C}-\mathrm{H}$ bonds of phenyl rings. The peaks at $997 \mathrm{~cm}^{-1}$ were related to the inplane flexural vibration of the benzene ring. For PAH C78, the peaks at 1257 (1258) and 1330 (1332) $\mathrm{cm}^{-1}$ were D band, and the peaks at 1596 (1597) $\mathrm{cm}^{-1}$ were $\mathrm{G}$ band. 


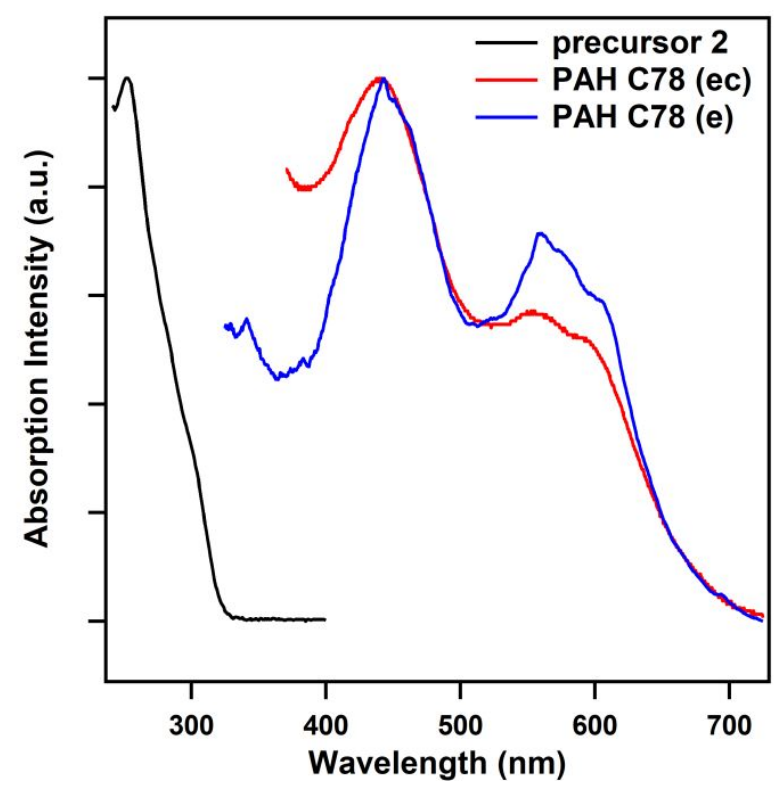

Figure S14. Absorption spectra of precursor 2 and electrochemically (ec) and chemically (c) synthesized PAH C78. The absorption peaks of PAH C78 films show an apparent red shift compared to their precursors, which clearly testifies the formation of an extended conjugation. 


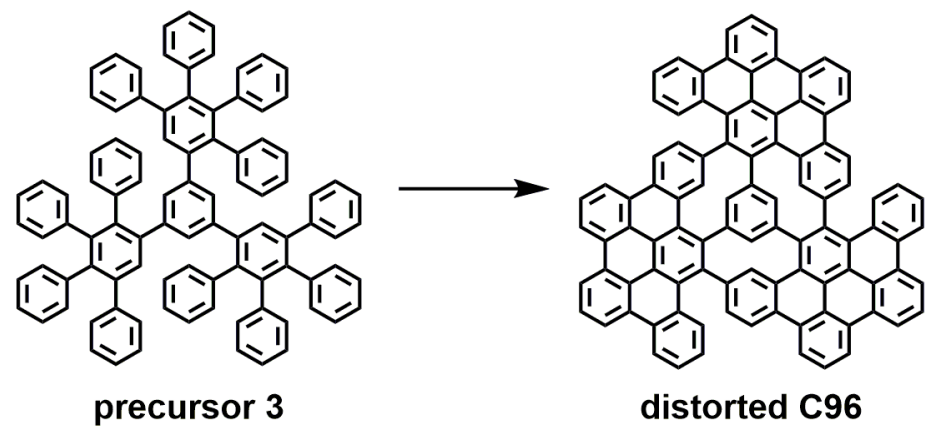

Figure S15. Proposed electrolysis reaction of precursor 3 with a low potential of $1.65 \mathrm{~V}$. 


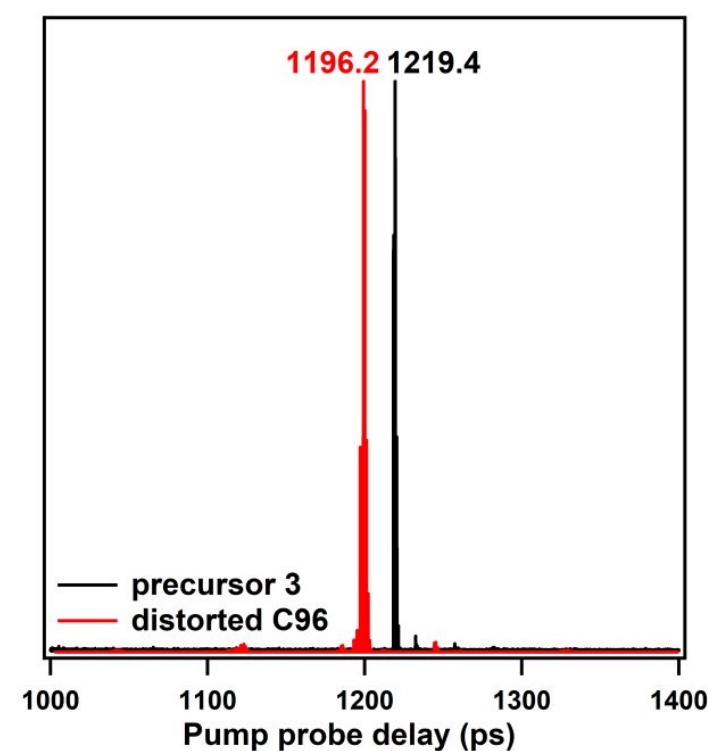

Figure S16. MALDI-TOF-MS of precursor 3 and distorted PAH C96. 

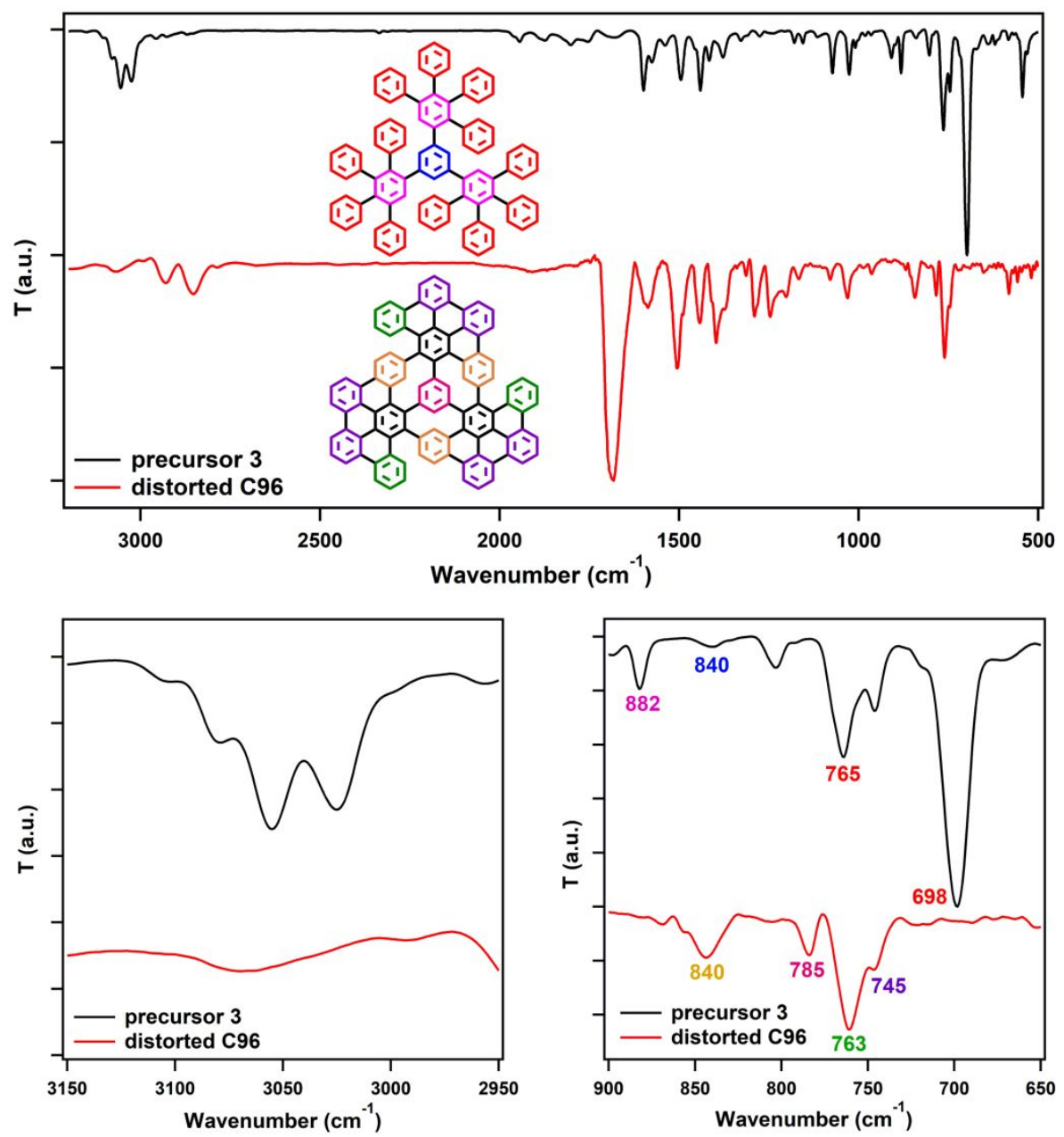

Figure S17. FT-IR of precursor 3 and distorted PAH C96 powder. (a) $3250-500 \mathrm{~cm}^{-1}$. (b) $3150-2950 \mathrm{~cm}^{-1}$. (c) $900-650 \mathrm{~cm}^{-1}$.

For precursor 3, the medium strong bands at $\sim 3050 \mathrm{~cm}^{-1}$ were related to the $\mathrm{C}-\mathrm{H}$ stretching vibration of the monosubstituted phenyl rings. The medium strong bands appeared at 765 and $698 \mathrm{~cm}^{-1}$ were contributed to $\mathrm{C}-\mathrm{H}$ twisting vibrations of the monosubstituted phenyl rings (phenyl units in red). The peaks located at $840 \mathrm{~cm}^{-1}$ were produced by the $\mathrm{C}-\mathrm{H}$ twisting vibrations of the 1,3,5-substituted benzenes (phenyl units in blue). And the peaks located at $882 \mathrm{~cm}^{-1}$ were produced by the $\mathrm{C}-\mathrm{H}$ twisting vibrations of the 1,2,3,4,5pentasubstituted benzene (phenyl units in purple). For distorted PAH C96, the peaks located at $763 \mathrm{~cm}^{-1}$ were produced by the $\mathrm{C}-\mathrm{H}$ twisting vibrations of the 1,2-disubstituted benzenes (phenyl units in green). The peaks located at $785 \mathrm{~cm}^{-1}$ were produced by the $\mathrm{C}-\mathrm{H}$ twisting vibrations of the 1,2,3-trisubstituted benzene benzenes (phenyl units in pink). The peaks located at $840 \mathrm{~cm}^{-1}$ were produced by the $\mathrm{C}-\mathrm{H}$ twisting vibrations of the 1,2,4-trisubstituted benzene benzenes (phenyl units in orange). The peaks located at $745 \mathrm{~cm}^{-1}$ were produced by the $\mathrm{C}-\mathrm{H}$ twisting vibrations of the 1,3,5-trisubstituted benzene benzenes (phenyl units in deep purple). 


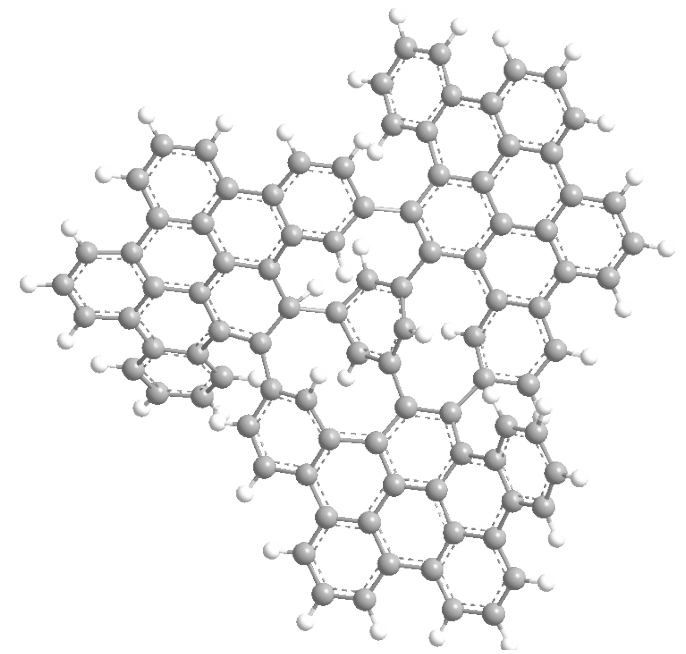

Figure S18. The structure of the distorted C96 simulated using DFT calculations. 


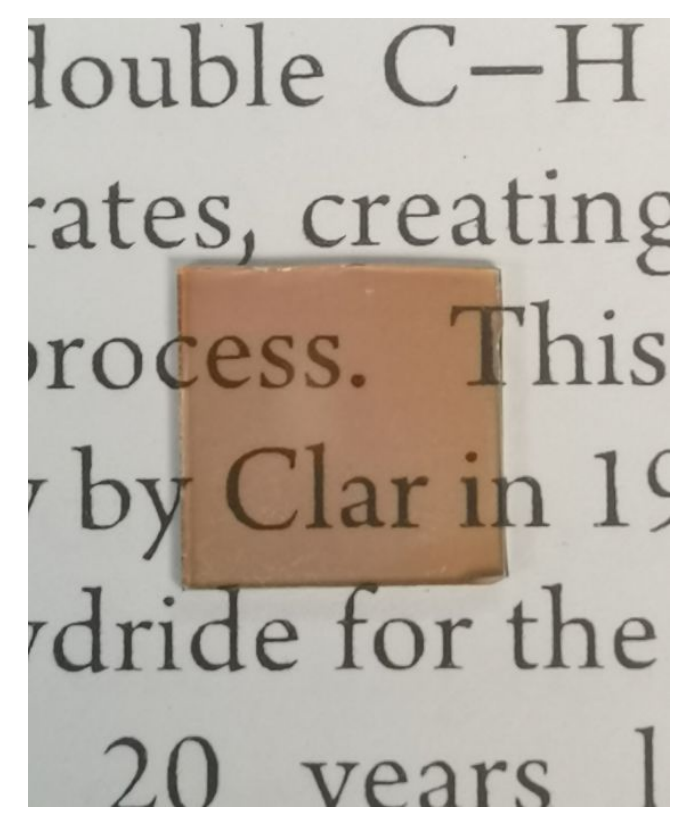

Figure S19. A photo of the transparent PAH C96 film on ITO $\left(1.0 \times 1.0 \mathrm{~cm}^{2}\right.$ in area). 

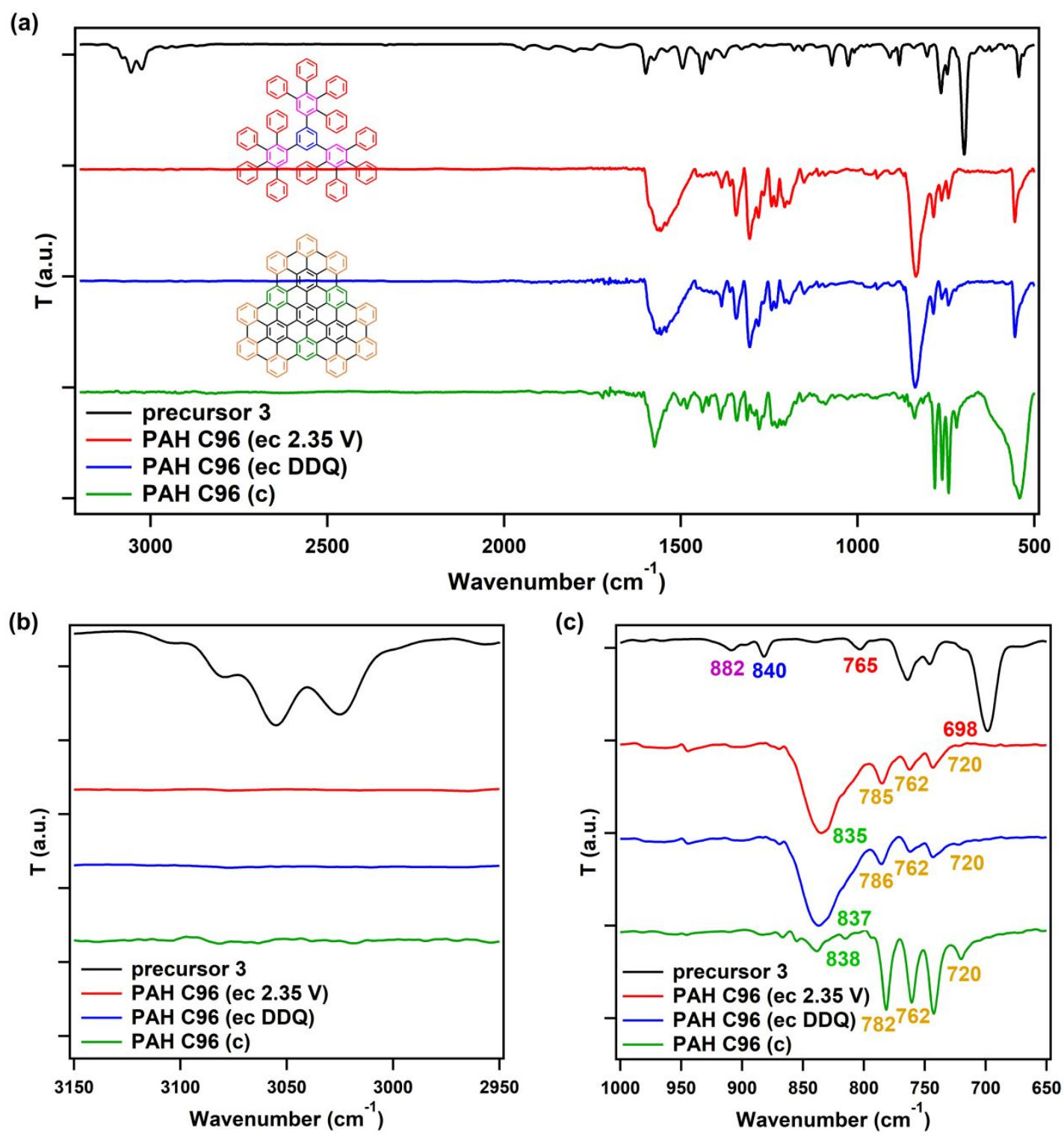

Figure S20. FT-IR of precursor 3 and electrochemically (ec) and chemically (c) synthesized PAH C96 powder. (a) $3250-500 \mathrm{~cm}^{-1}$. (b) $3150-2950 \mathrm{~cm}^{-1}$. (c) $900-650 \mathrm{~cm}^{-1}$.

For precursor 3, the medium strong bands at $\sim 3050 \mathrm{~cm}^{-1}$ were related to the $\mathrm{C}-\mathrm{H}$ stretching vibration of the monosubstituted phenyl rings. The medium strong bands appeared at 765 and $698 \mathrm{~cm}^{-1}$ were contributed to $\mathrm{C}-\mathrm{H}$ twisting vibrations of the monosubstituted phenyl rings (phenyl units in red). The peaks located at $840 \mathrm{~cm}^{-1}$ were produced by the $\mathrm{C}-\mathrm{H}$ twisting vibrations of the 1,3,5-substituted benzenes (phenyl units in blue). And the peaks located at $882 \mathrm{~cm}^{-1}$ were produced by the $\mathrm{C}-\mathrm{H}$ twisting vibrations of the 1,2,3,4,5pentasubstituted benzene (phenyl units in purple). For PAH C96, the peaks located at 785 (786, 782), 762, and $720 \mathrm{~cm}^{-1}$ were produced by the $\mathrm{C}-\mathrm{H}$ twisting vibrations of the 1,2,3trisubstituted benzene benzenes (phenyl units in orange). The peaks located at $835(837,838)$ $\mathrm{cm}^{-1}$ were produced by the $\mathrm{C}-\mathrm{H}$ twisting vibrations of the penta-substituted benzenes (phenyl units in green). 


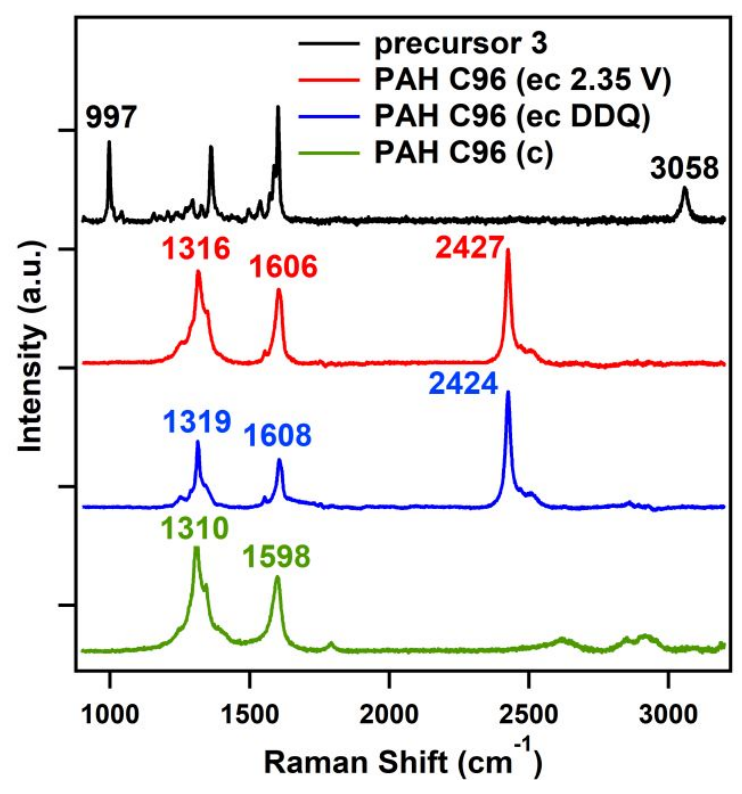

Figure S21. Raman spectra of precursor 3 and electrochemically (ec) and chemically (c) synthesized PAH C96. For precursor 3, the peaks at $3058 \mathrm{~cm}^{-1}$ were related to the stretching vibrational bands of $\mathrm{C}-\mathrm{H}$ bonds of phenyl rings. The peaks at $997 \mathrm{~cm}^{-1}$ were related to the inplane flexural vibration of the benzene ring. For PAH C96, the peak at $1316(1319,1310) \mathrm{cm}^{-}$ ${ }^{1}$ were $\mathrm{D}$ band, the peaks at $1606(1608,1598) \mathrm{cm}^{-1}$ were $\mathrm{G}$ band, and the peaks at 2427 (2424) $\mathrm{cm}^{-1}$ were $2 \mathrm{D}$ band. 


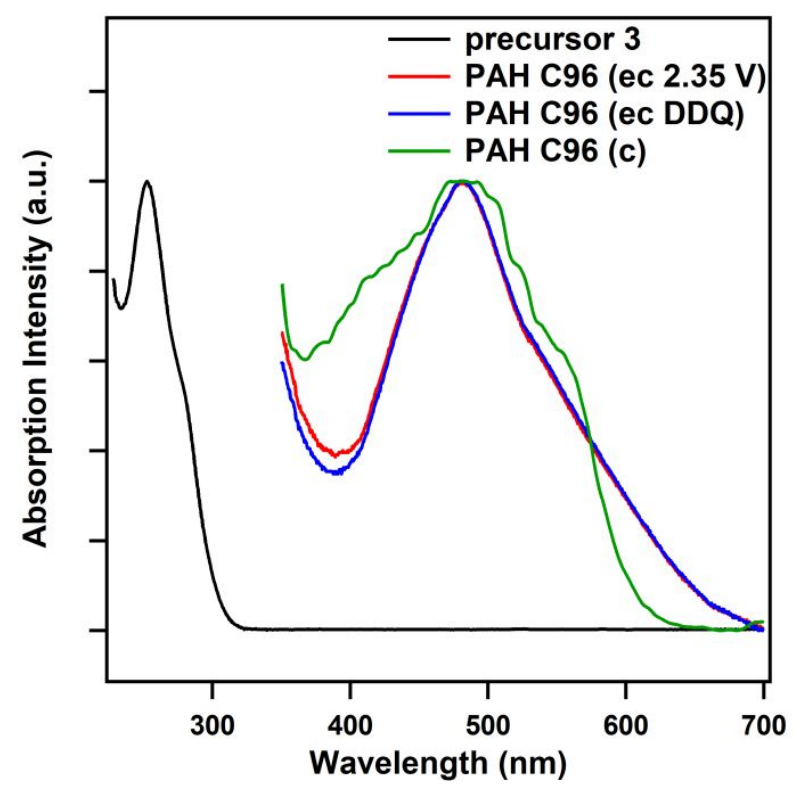

Figure S22. Absorption spectra of precursor 3 and electrochemically (ec) and chemically (c) synthesized PAH C96. The absorption peaks of PAH C96 films show an apparent red shift compared to their precursors, which clearly testifies the formation of an extended conjugation. 


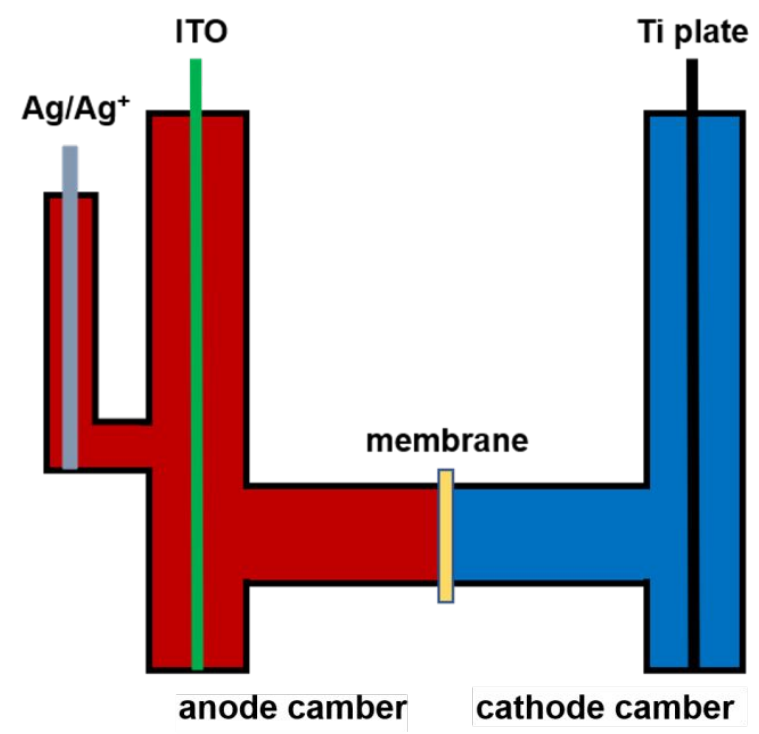

Figure S23. Schematic diagram of H-type cell. 


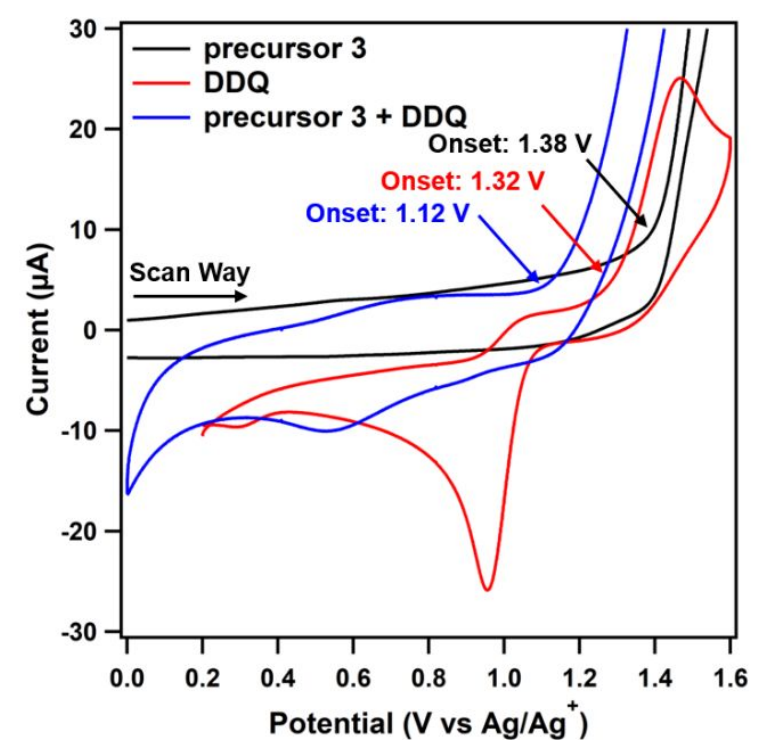

Figure S24. CV profiles ( $1^{\text {st }}$ cycle) of a solution of precursor 3 with a scan rate of $0.05 \mathrm{~V} \mathrm{~s}^{-1}$. 


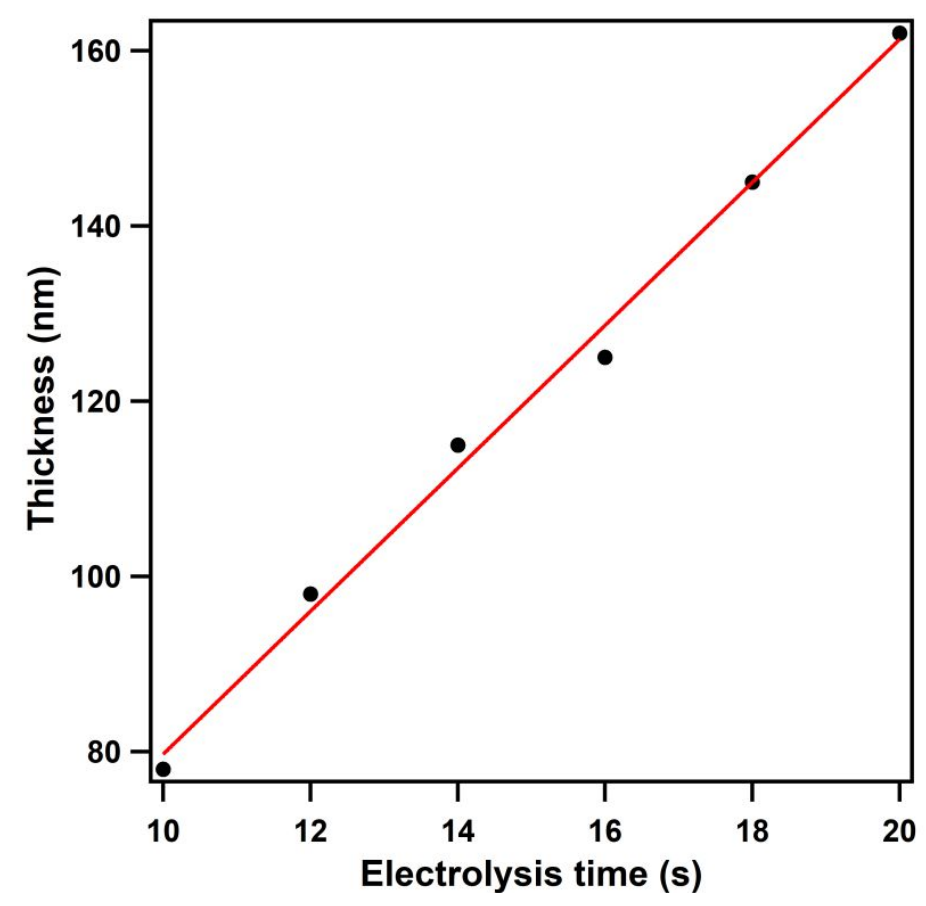

Figure S25. Film thickness versus the CV cycle numbers for PAH C96 films with DDQ as the mediator. 


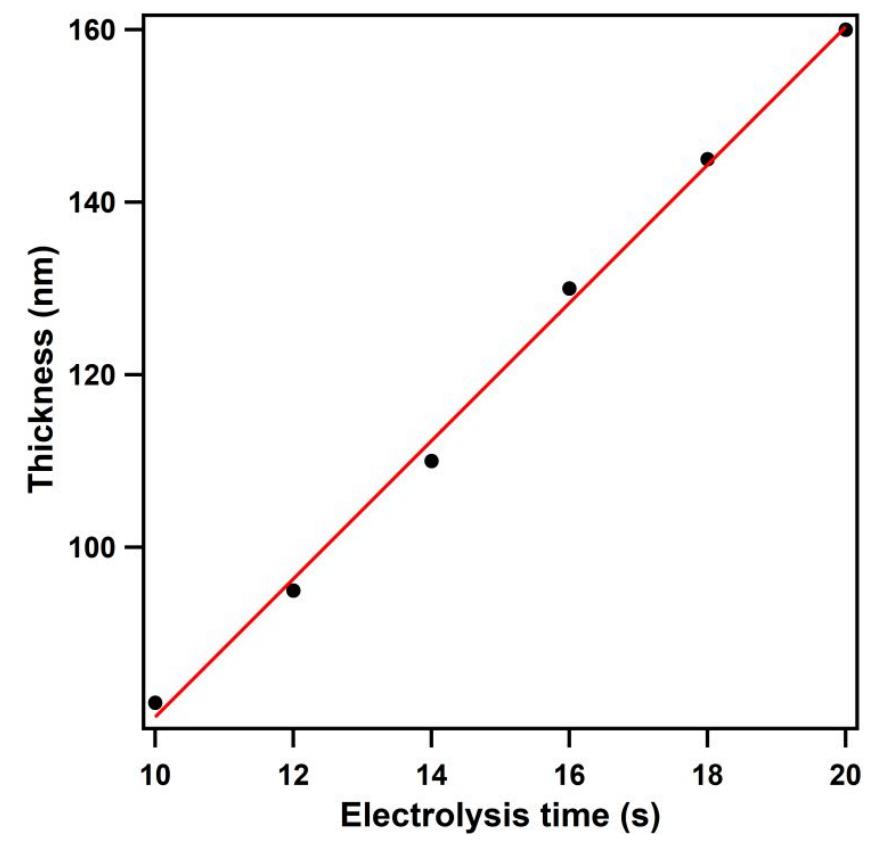

Figure S26. Film thickness versus the CV cycle numbers for PAH C96 films under high potential of $2.35 \mathrm{~V}$. 

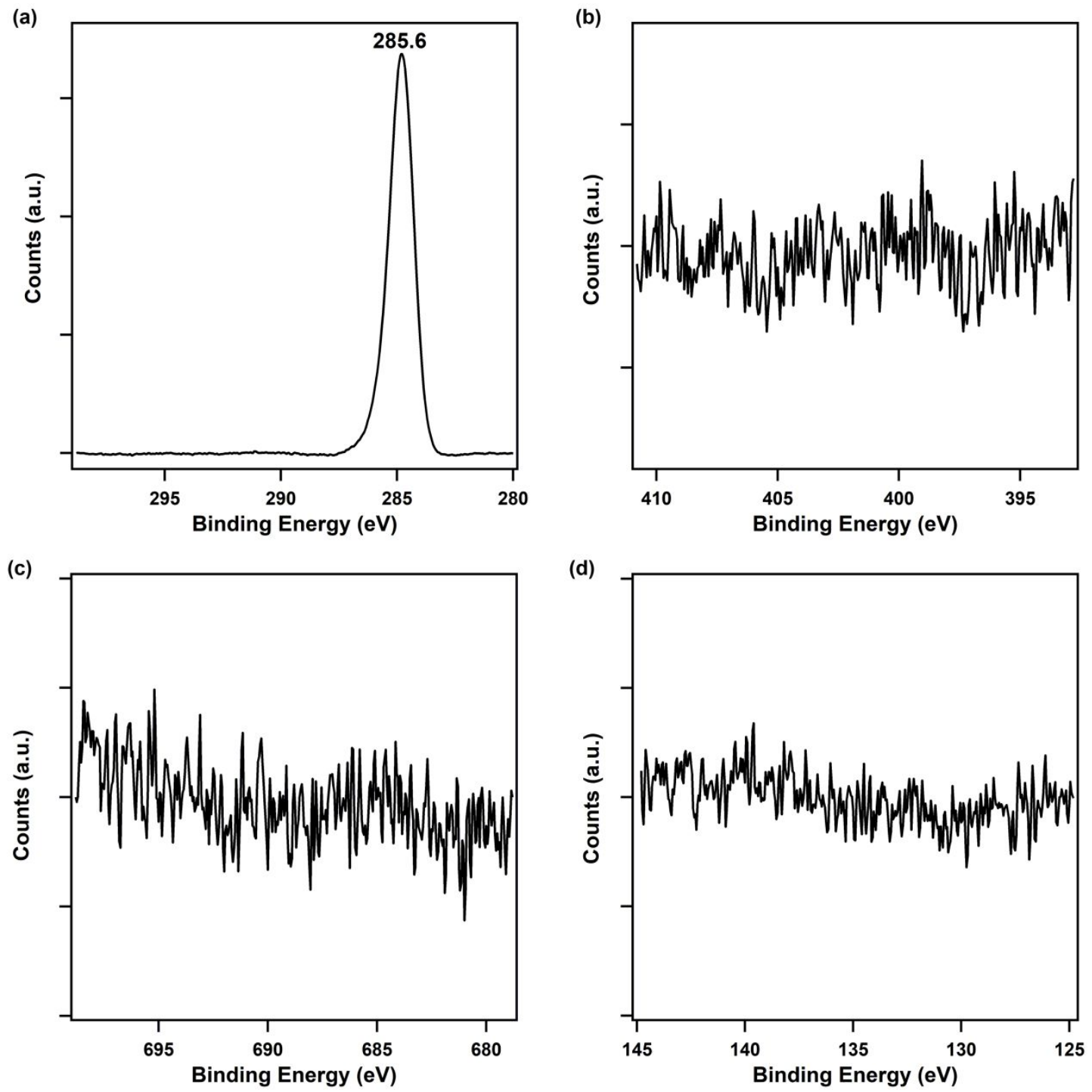

Figure S27. XPS of pristine PAH C60 films. (a) C1s. (b) N1s. (c) P2p. (d) F1s. 

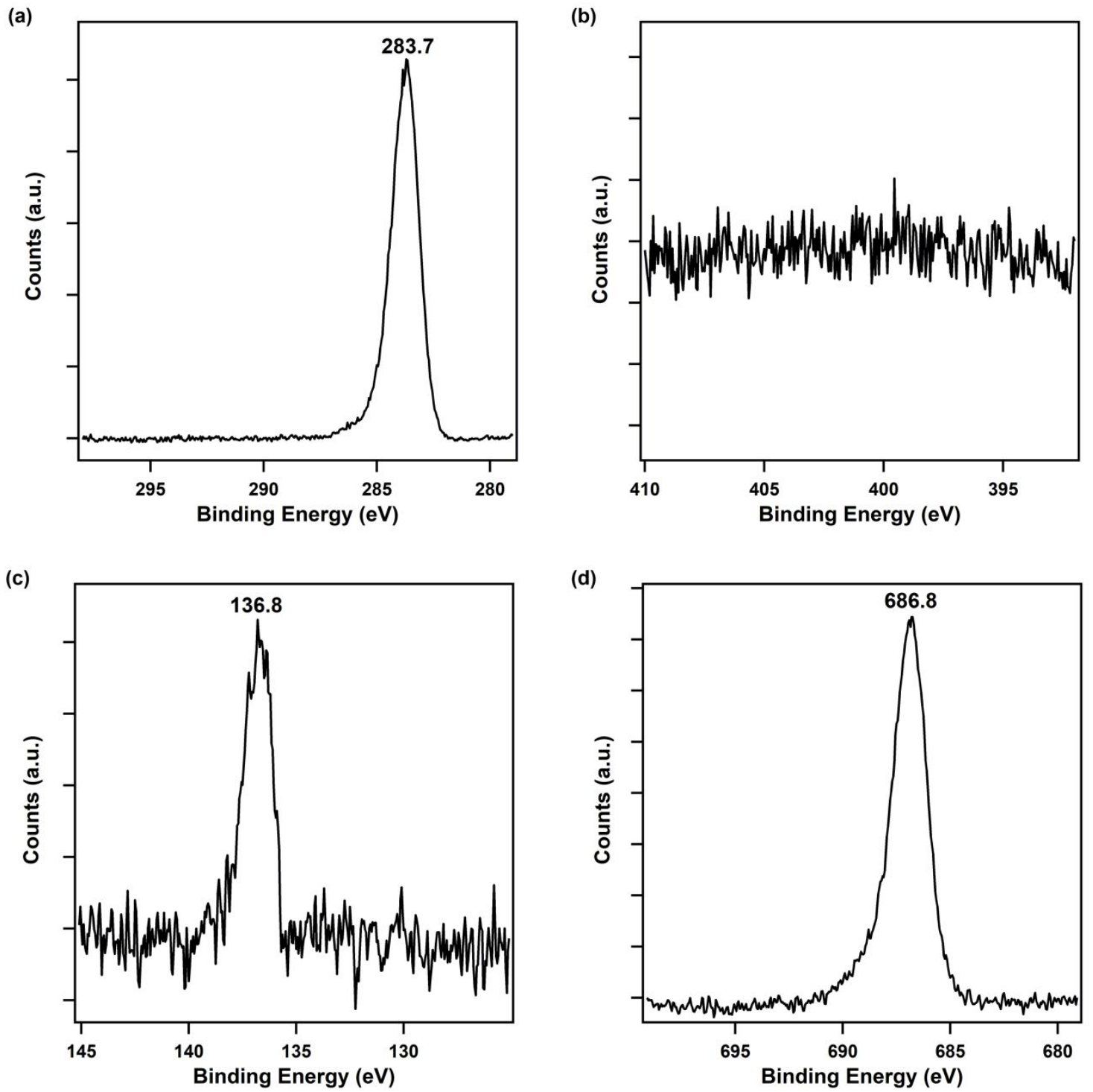

Figure S28. XPS of 1.30 V doped PAH C60 films. (a) C1s. (b) N1s. (c) P2p. (d) F1s. 

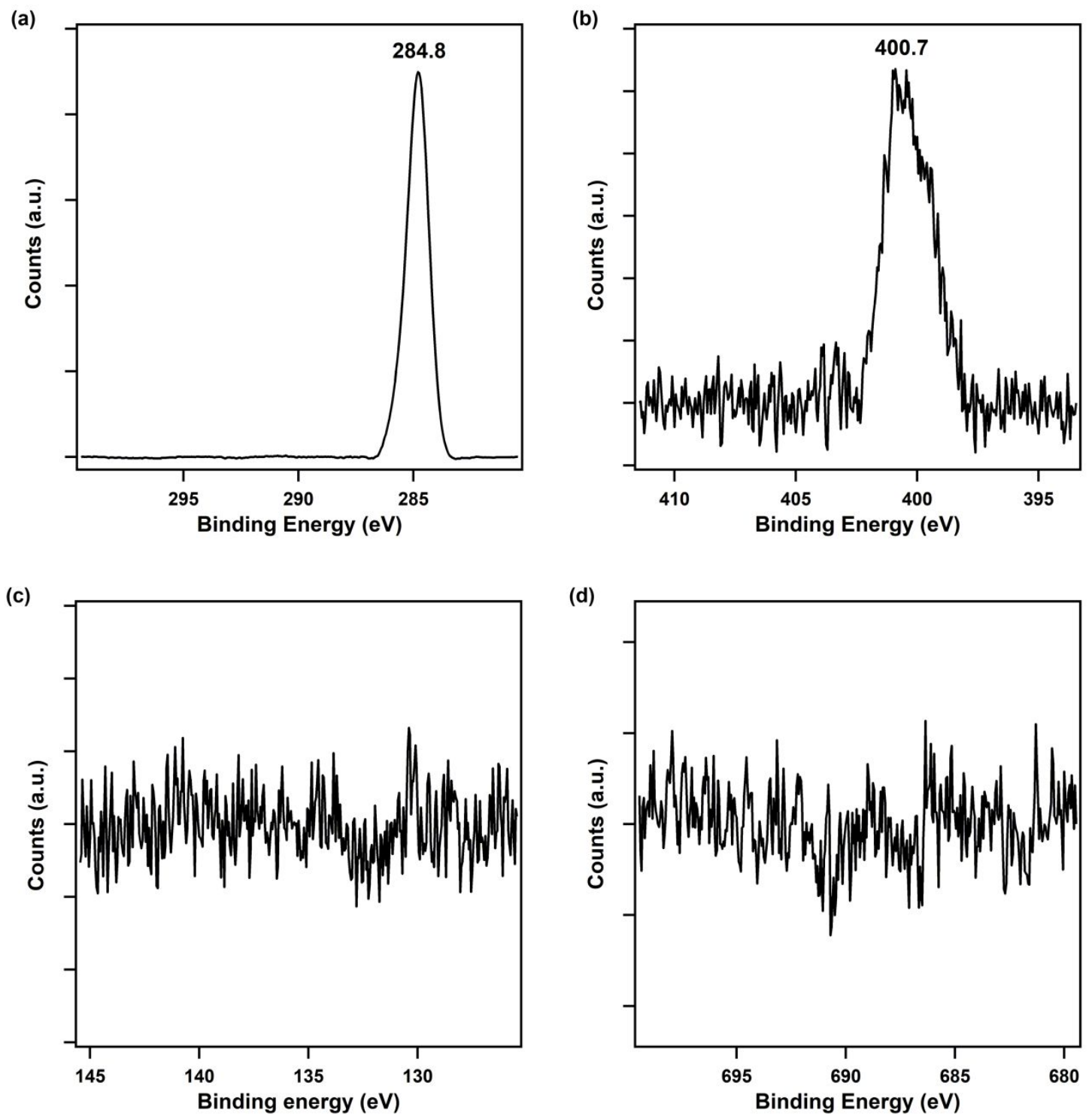

Figure S29. XPS of -1.90 V doped PAH C60 films. (a) C1s. (b) N1s. (c) P2p. (d) F1s. 

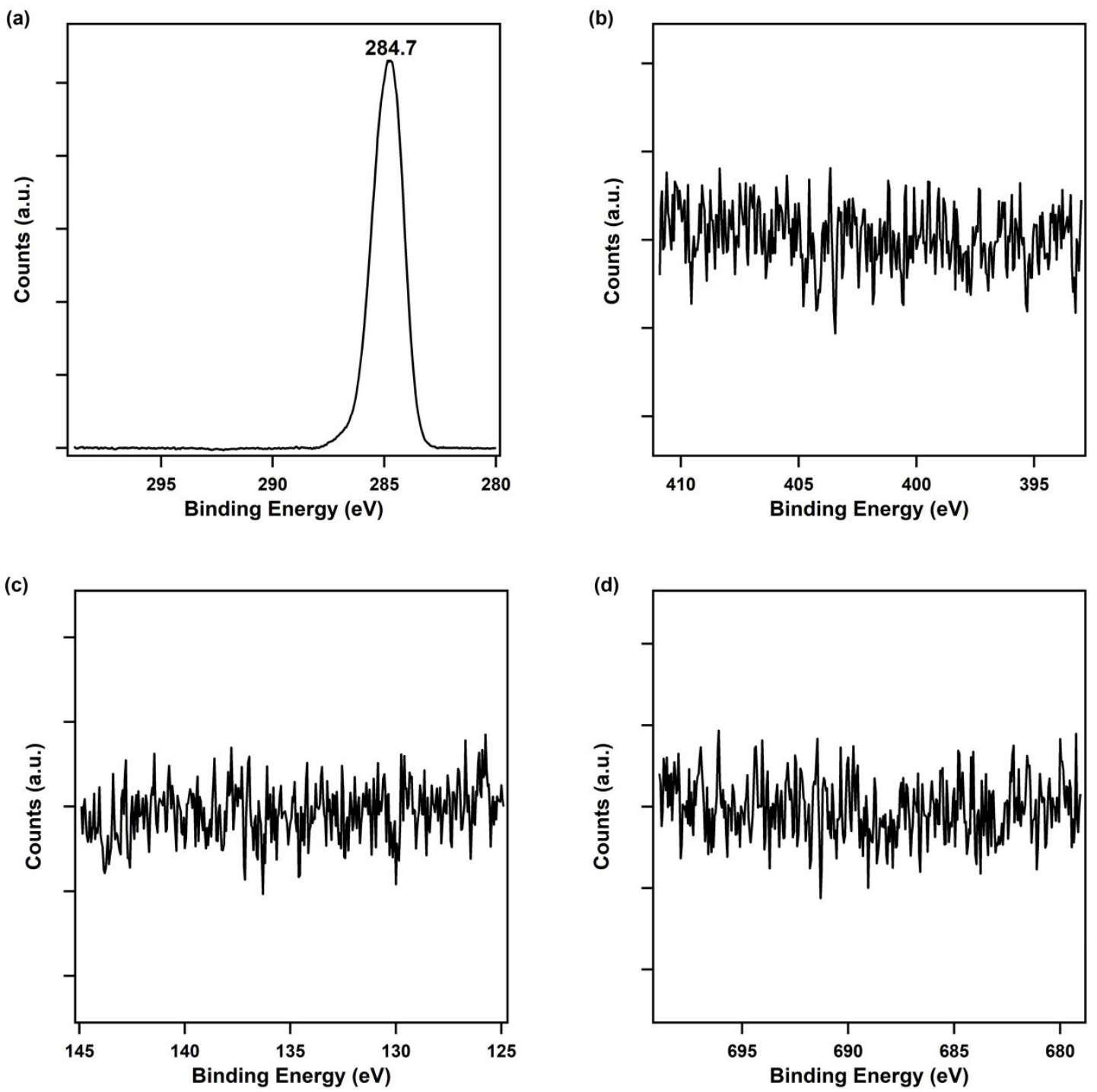

Figure S30. XPS of pristine PAH C78 films. (a) C1s. (b) N1s. (c) P2p. (d) F1s. 

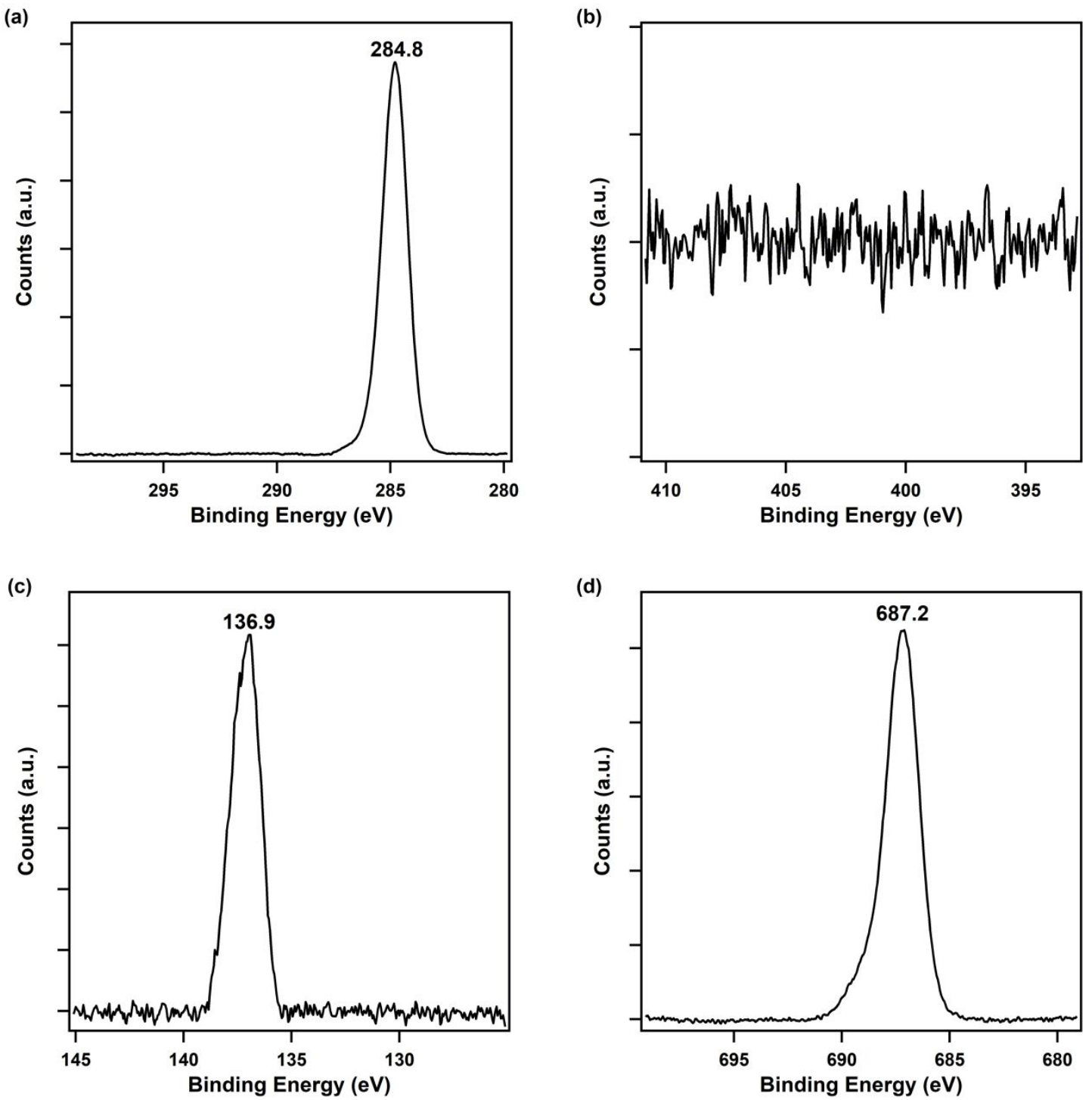

Figure S31. XPS of $0.57 \mathrm{~V}$ doped PAH C78 films. (a) C1s. (b) N1s. (c) P2p. (d) F1s. 

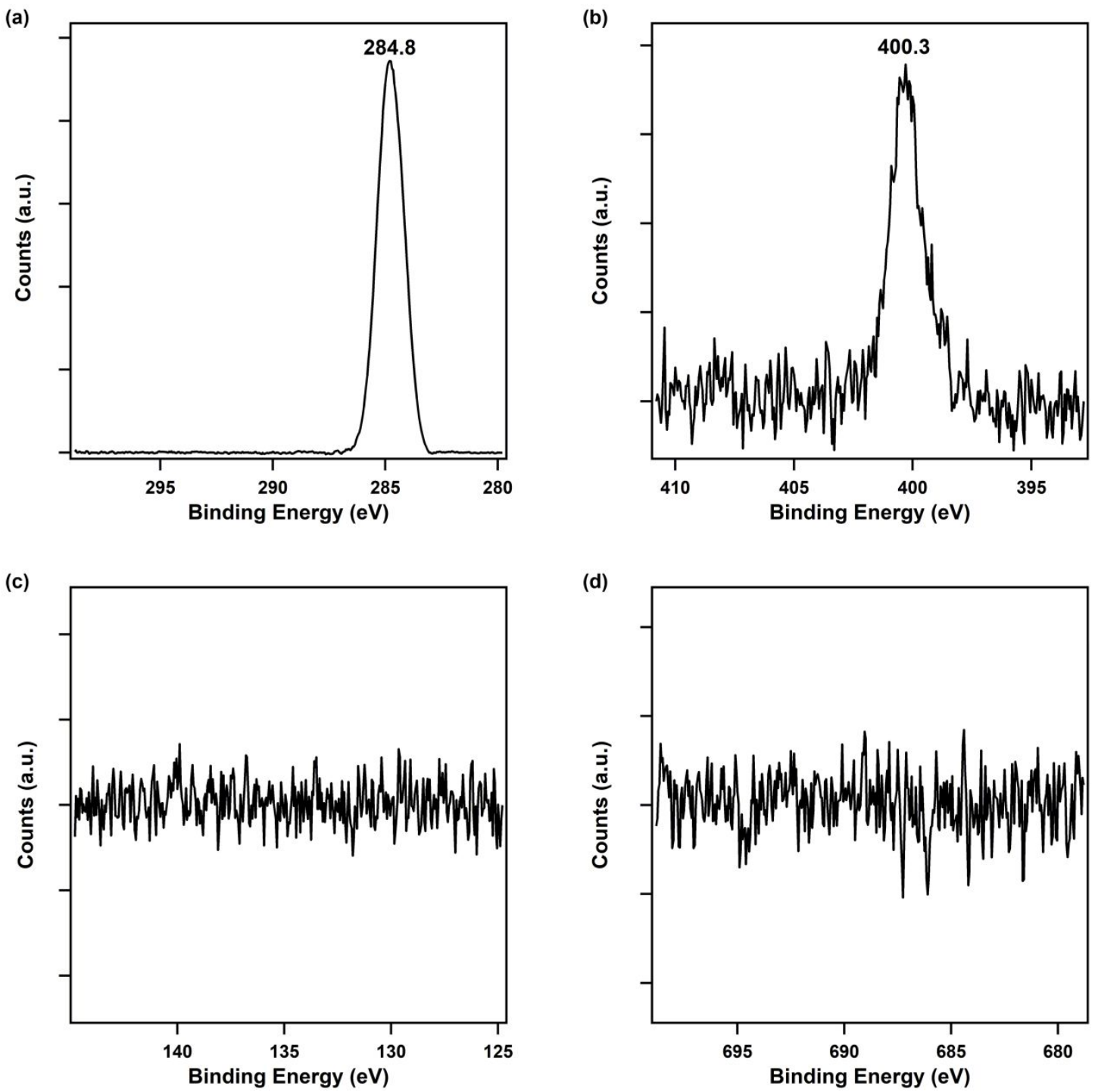

Figure S32. XPS of -1.60 V doped PAH C78 films. (a) C1s. (b) N1s. (c) P2p. (d) F1s. 

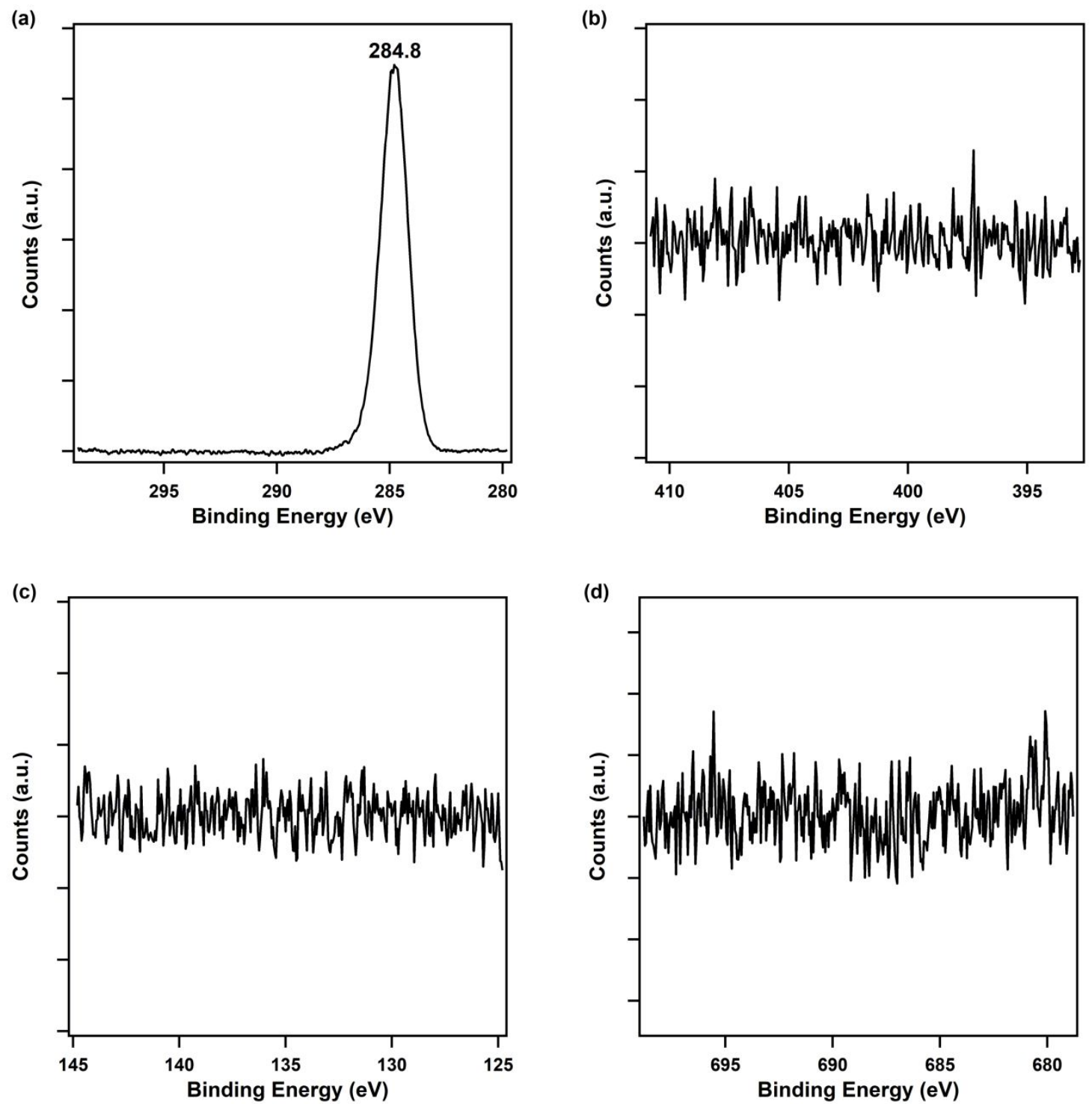

Figure S33. XPS of pristine PAH C96 films. (a) C1s. (b) N1s. (c) P2p. (d) F1s. 

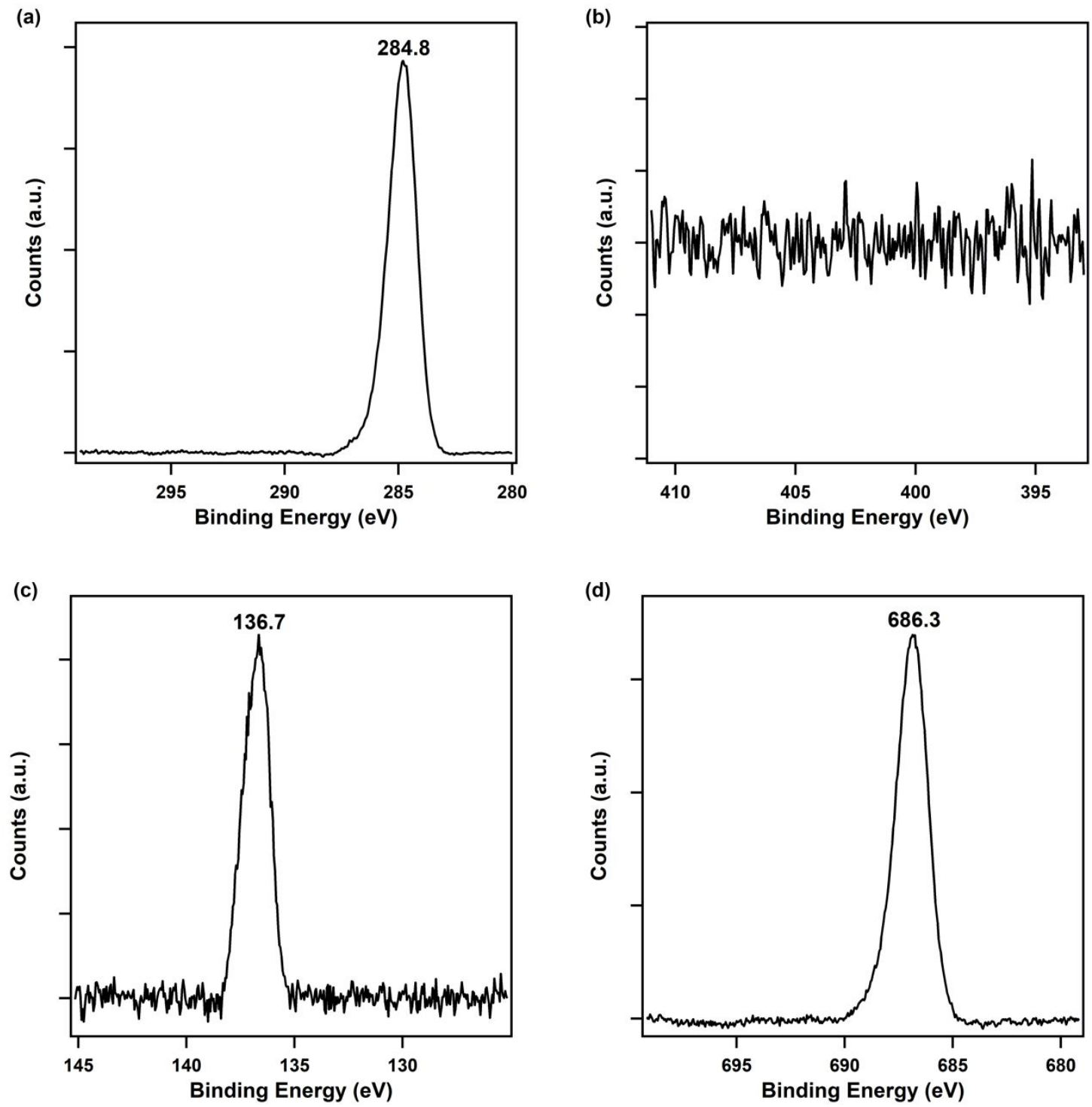

Figure S34. XPS of 0.95 V doped PAH C96 films. (a) C1s. (b) N1s. (c) P2p. (d) F1s. 

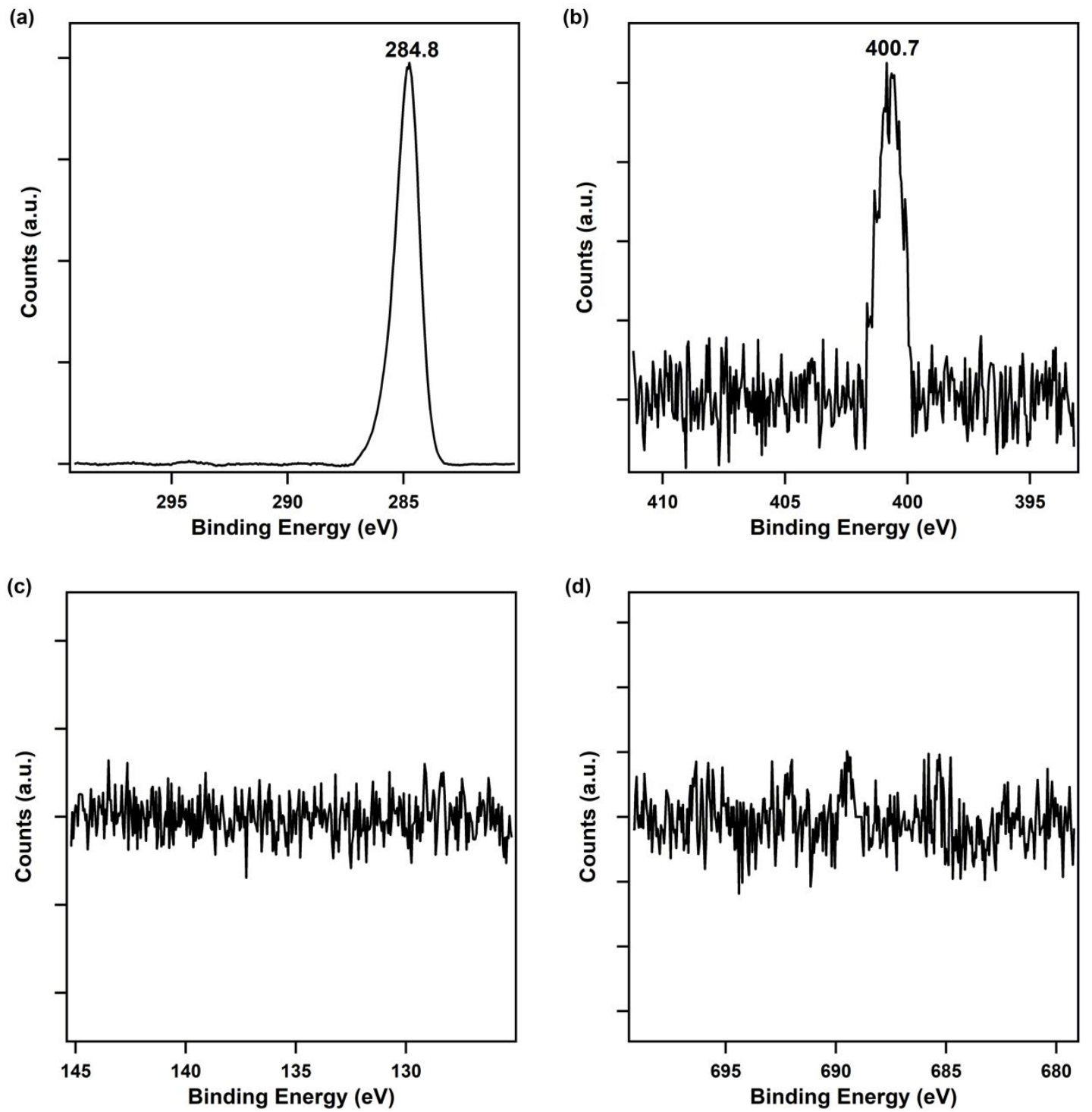

Figure S35. XPS of -1.77 V doped PAH C96 films. (a) C1s. (b) N1s. (c) P2p. (d) F1s. 


\section{Supporting References}

S1. Feng, X.; Wu, J.; Ai, M.; Pisula, W.; Zhi, L.; Rabe, J. P.; Müllen, K. Triangle-Shaped Polycyclic Aromatic Hydrocarbons. Angew. Chem. Int. Ed. 2007, 46, 3033-3036.

S2. Böhme, T.; Simpson, C. D.; Müllen, K.; Rabe, J. P. Current-Voltage Characteristics of a Homologous Series of Polycyclic Aromatic Hydrocarbons. Chem. Eur. J. 2007, 13, 7349-7357.

S3. Tomović, Ž.; Watson, M. D.; Müllen, K. Superphenalen-based Columnar Liquid Crystals. Angew. Chem. Int. Ed. 2004, 43, 755-758.

S4. Hohenberg, P.; Kohn, W. Inhomogeneous Electron Gas. Phys. Rev. 1964, 136, B864.

S5. Kohn, W.; Sham, L. J. Self-Consistent Equations Including Exchange and Correlation Effects. Phys. Rev. 1965, 140, A1133.

S6. Clark, S. J.; Segall, M. D.; Pickard, C. J.; Hasnip, P. J.; Probert, M. J.; Refson, K.; Payne, M. C. First Principles Methods Using CASTEP. Z. Kristallogr. 2005, 220, 567570.

S7. Perdew, J. P.; Burke, K.; Ernzerhof, M. Generalized Gradient Approximation Made Simple. Phys. Rev. Lett. 1996, 77, 3865-3868.

S8. Grimme, S. Accurate Description of van der Waals Complexes by Density Functional Theory Including Empirical Corrections. J. Comput. Chem. 2004, 25, 1463-1473.

S9. Grimme, S. Semiempirical GGA-Type Density Functional Constructed with a LongRange Dispersion Correction. J. Comput. Chem. 2006, 27, 1787-1799.

S10. González-Meza, O. A.; Larios-Durán, E. R.; Gutiérrez-Becerra, A.; Casillas, N.; Escalante, J. I.; Bárcena-Soto, M. Development of a Randles-Ševčík-like Equation to Predict the Peak Current of Cyclic Voltammetry for Solid Metal Hexacyanoferrates. $J$ Solid State Electrochem 2019, 23, 3123-3133.

S11. Konopka, S. J.; McDuffie, B. Diffusion Coefficients of Ferri- and Ferrocyanide Ions in Aqueous Media, Using Twin-Electrode Thin-Layer Electrochemistry. Anal. Chem. 1970, $42,1741-1746$. 